\title{
Deformación compresiva cuaternaria en la Cordillera Principal de Chile central (Cajón del Maipo, este de Santiago)
}

\author{
Alain Lavenu', José Cembrano² \\ ${ }^{1}$ LMTG-Université de Toulouse-CNRS-IRD-OMP, 14 Avenue Edouard Belin, F-31400 Toulouse, France. \\ alavenu2@orange.fr \\ 2 Departamento Ciencias Geológicas, Universidad Católica del Norte, Avenida Angamos 0610, Antofagasta, Chile. \\ cembrano@gmail.com
}

RESUMEN. El estudio geológico y estructural detallado de sedimentos recientes en el valle del río Maipo (Cajón del Maipo), al este de Santiago, muestra la existencia de una deformación en compresión con fallas inversas y pliegues de arrastre contemporáneos. Estas estructuras son cinemáticamente compatibles con una dirección de esfuerzo cercana a $\mathrm{N}-\mathrm{S}\left(\mathrm{N} 338^{\circ} \mathrm{E}\right)$ que afecta también a las unidades de roca más antiguas (Formación Abanico), que constituyen el sustrato de las terrazas aluviales cuaternarias. En estas rocas del sustrato, se superponen dos episodios de deformación, el primero de edad neógena (post $9 \mathrm{Ma}$ ), caracterizado por un $\sigma 1$ de dirección E-O; el segundo cuaternario y con un $\sigma 1$ cercano a N-S. Este último episodio de deformación resultaría de la partición regional del vector de convergencia oblicua entre las placas de Nazca y Sudamérica; un 'buttress' a los $33^{\circ} \mathrm{S}$ produciría el gradiente de velocidad latitudinal necesario en el antearco para conducir a un acortamiento norte-sur. La sismicidad cortical superficial en la parte interna del antearco (Cordillera Principal) es -al menos en parte- compatible con la dirección de compresión obtenida a partir del análisis cinemático de las fallas mesoscópicas.

Palabras claves: Antearco, Neotectónica, Deformación, Esfuerzo, Cuaternario, Chile central, Andes.

\begin{abstract}
Quaternary compressional deformation in the Main Cordillera of Central Chile (Cajón del Maipo, east of Santiago). A detailed study of recent sediments in the Maipo River Valley (Cajón del Maipo), east of Santiago, shows a compressive deformation documented by coeval reverse faults and drag-folds. These structures are characteristic of a principal stress direction trending roughly $\mathrm{N}-\mathrm{S}\left(\mathrm{N} 338^{\circ} \mathrm{E}\right)$ that also affects the older sediments of the Abanico Formation constituting the bedrock of the Quaternary alluvial terraces. Two deformation episodes are superposed in the bedrock: a Neogene deformation event (post $9 \mathrm{Ma}$ ), having an E-W-trending $\sigma 1$, and a late Quaternary event with $\sigma 1$ roughly trending N-S. The latter would be the result of regional-scale partitioning of the oblique convergence vector between the Nazca and South American Plates; a buttress at $33^{\circ} \mathrm{S}$ would produce a north-south velocity gradient in the forearc leading to regional, north-south shortening. Shallow crustal seismicity in the inner forearc (Main Cordillera) is -at least in part- compatible with the compression direction as obtained from the kinematic analysis of mesoscopic fault-slip data.
\end{abstract}

Keywords: Forearc, Neotectonics, Strain, Stress, Quaternary, Central Chile, Andes. 


\section{Introducción}

En los Andes centrales chilenos, al este de la ciudad de Santiago, la cuenca hidrográfica superior del río Maipo (y de los ríos Colorado, Yeso y Volcán) erosiona diversas unidades geológicas: las altas cumbres volcánicas cuaternarias que pasan los $6.000 \mathrm{~m}$ y que constituyen el límite con Argentina (volcanes Tupungato, Marmolejo, San José, Maipo), los afloramientos marinos y continentales del Jurásico-Cretácico, un importante cordón volcánico-sedimentario continental; las formaciones Abanico y Farellones y unidades intrusivas miocénicas (Thiele, 1980).

El río Maipo escurre por un valle profundo (Cajón del Maipo) de la Cordillera Principalen dirección aproximada E-O. Se trata de un valle en que se depositaron, durante el Cuaternario, coluvios, abanicos aluviales o conos de deyección, depósitos fluviales, lacustres, glaciares, flujos de barro y detritos que a su vez soportaron la formación de distintas terrazas aluviales.

En este artículo presentamos y discutimos datos neotectónicos nuevos y observaciones geomorfológicas relacionadas con la deformación de los depósitos principalmente fluviales que forman la Alta Terraza cuaternaria del río Maipo. Estos nuevos antecedentes documentan una dirección de compresión norte-sur durante el Cuaternario, cuyo origen se discute en el marco de la evolución neotectónica de esta parte de los Andes centrales.

\section{Metodología}

Con el propósito de conocer la geometría y la cinemática de la deformación que afecta a los depósitos cuaternarios y rocas meso-cenozoicas subyacentes de la cordillera de Chile central se combinó el análisis de imágenes satelitales y fotografías aéreas, geomorfología de campo y análisis estructural de fallas y estrías en sitios clave. La observación de imágenes satelitales LANSAT 1:250.000 y de fotografías aéreas 1:60.000 (IGM), permitió la identificación de los lineamientos principales y las zonas susceptibles de exhibir evidencia de deformación frágil en el terreno. La revisión de la cartografía topográfica, a escala de 1:50.000, contribuyó significativamente a localizar de manera general grandes lineamientos, que pueden corresponder a las principales estructuras tectónicas, a lo largo de las cuales se concentra la deformación a escala más pequeña. El examen de la cartografía geológica disponible (Thiele, 1980), permitió conocer la naturaleza y edad de la mayoría de las unidades de roca fallada, y el mapeo geomorfológico de los depósitos fluviales recientes de la porción media del curso del río Maipo, permitió identificar la distribución y las relaciones espaciales entre las diferentes terrazas fluviales cuaternarias. La obtención de un datum de fallas, estrías e indicadores cinemáticos, en tres sitios de medición en que afloran tanto sedimentos cuaternarios como unidades meso-cenozoicas subyacentes, se utilizó para determinar las direcciones principales de esfuerzo y/o establecer los diferentes estados de esfuerzo, utilizando el algoritmo de inversión de datos de Carey-Mercier (1989) (en lo que concierne el tratamiento numérico de poblaciones de fallas y sus diferentes métodos de análisis como los modelos de deformación y las hipótesis básicas: cf. Lavenu y Cembrano, 1999a, b). Las direcciones principales de esfuerzo, obtenidas mediante este algoritmo para deformaciones pequeñas de edad reciente pueden considerarse aproximadamente coaxiales y recíprocas con las direcciones de acortamiento instantáneo que se han conseguido mediante el uso de otros métodos disponibles en la literatura. Marrett y Allmendinger (1990) muestran que los métodos que permiten la determinación de ejes principales de 'strain' infinitesimal a partir de un datum de fallas y estrías conducen a resultados muy similares a los de aquellos que entregan direcciones principales de esfuerzo.

En este trabajo se caracteriza la deformación neotectónica que ocurre durante el último régimen de esfuerzo (o deformación) existente en una región determinada y durante el régimen de deformación (y/o esfuerzo) actual. Si las fallas tienen una expresión morfológica actual debida a una ruptura o deformación de la superficie, las podemos calificar de fallas activas, sin desconocer las dificultades que existen para determinar la edad de su movimiento y a partir de cuándo la falla ya no es activa: 5.000 , $10.000,130.000$ o 500.000 años (Machette, 2000; Costa et al., 2006).

\section{Marco geológico y morfotectónico}

Los afloramientos estudiados se ubican en el flanco occidental de la Cordillera Principal, cercano al límite con la Depresión Central, también denominada Cuenca de Santiago (Fig. 1). En esta zona, el flanco occidental de la Cordillera Principal está constituido esencialmente por rocas volcánicas y volcano-sedi- 
mentarias continentales tales como tobas, brechas volcánicas, lavas y sedimentos de las formaciones
Abanico y Farellones y de rocas intrusivas granodioríticas del Mioceno (e.g., Thiele, 1980).

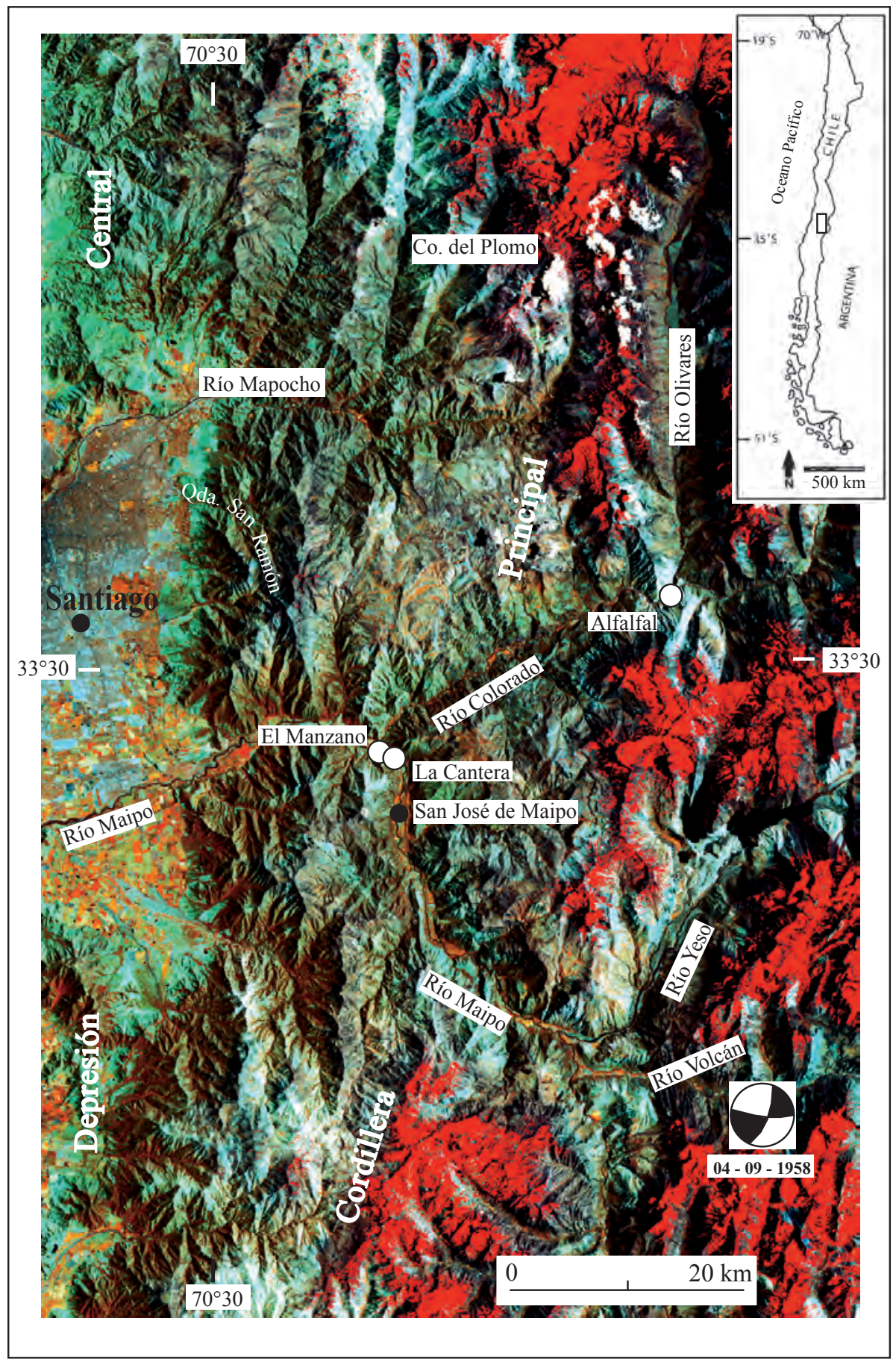

FIG. 1. Localización del área de estudio. Los dos primeros sitios de mediciones (círculos blancos) se encuentran, dos al SE de El Manzano, cerca de la confluencia de los ríos Maipo y Colorado (sitio La Cantera) y el tercero en Alfalfal, en la confluencia de los ríos Colorado y Olivares. Imagen satelital Landsat TM. En rojo, la nieve. El epicentro y mecanismo focal del sismo de las Melosas se encuentra en el extremo derecho de la figura. 
La formación Abanico tiene una edad eocena tardía a miocena temprana-media, determinada con dataciones K-Ar y ${ }^{40} \mathrm{Ar} /{ }^{39} \mathrm{Ar}$ entre 37,5-31,5 Ma (Charrier et al., 1996) y 29-28 Ma (Fuentes, 2004), así como por fauna fósil del Eoceno (Flynn et al., 2003). En el sector del Aconcagua, al norte de Santiago, se establecieron edades entre 28-17,4 Ma (Gana y Wall, 1997; Elgueta et al., 2000). Un poco más al norte de este sector las edades obtenidas son de 30,9-21,6 Ma (Nyström et al., 2003), 27-20 Ma (Kay y Mpodozis, 2002) y tan jóvenes como 16,1 Ma (Kay y Kurtz, 1995: en Charrier et al., 2002).

Desde los años sesenta, el límite entre la Depresión Central y la Cordillera Principal ha sido tradicionalmente visto como fallas de borde de graben (Carter y Aguirre, 1965; Aubouin et al., 1973). Sin embargo, la geometría y la cinemática actual de este borde no corresponden a un graben limitado por fallas normales, ya que la mayoría de las fallas observadas a lo largo de este límite son más bien de rumbo, rumbo-inversas (Lavenu y Cembrano, 1999b) o inversas (Rauld, 2002; Ormeño, 2007).

Esta depresión está rellena con más de $500 \mathrm{~m}$ de depósitos fluviales, aluviales, fluvioglaciales a glaciales (Araneda et al., 2000). Rauld (2002) definió tres unidades que yacen sobre las rocas fundamentales de la Formación Abanico: 1. una 'Unidad Antigua' de posible edad del Terciario superior-Cuaternario, 2. una 'Unidad Cuaternaria Joven intermedia' estimada del Cuaternario, en la cual se puede encontrar acumulaciones de ceniza, y finalmente 3. una 'Unidad Cuaternaria Reciente'. En esta región de Chile, hay numerosos afloramientos de depósitos de tobas jóvenes y sólo algunas han sido datadas. En la Unidad Cuaternaria Joven, una capa de ceniza, la Ignimbrita Pudahuel, fue datada del Plioceno superior en 2,3 $\pm 0,3$ Ma y 2,2 $\pm 0,3 \mathrm{Ma}$ por Wall et al. (2001) y del Pleistoceno medio en 0,47 $\pm 0,07$ Ma y 0,44 $\pm 0,08$ Ma por Stern et al. (1984). Dataciones en curso, por el método (U-Th)/He, sugieren edades significativamente más jóvenes que los 0,45 Ma para la ignimbrita Pudahuel (Lara, comunicación oral, 2007). La ignimbrita Pudahuel aflora, principalmente, en los bordes de la Cuenca de Santiago a unos 470/490 m s.n.m. en la parte NO, a $400 \mathrm{~m}$ s.n.m. en la parte oeste y entre 750 y 1.000 m s.n.m. en la parte este (Fig. 2).

La edad de la Ignimbrita Pudahuel y la del comienzo de su erosión son consistentes con los resul- tados de Le Roux et al. (2005) según los cuales los últimos sedimentos marinos encontrados en la costa tienen una edad entre $2 \mathrm{Ma}$ y $1 \mathrm{Ma}$, seguidos por la emersión de la línea de costa. Eso correspondería al inicio de la erosión de la Cordillera Principal en levantamiento o ya levantada (Farías et al., 2005) y también de la Depresión Central y de la Cordillera de la Costa (Riquelme et al., 2003; Riquelme et al., 2007). Estos depósitos de tobas se habrían depositado sobre una superficie de erosión, con pendiente hacia la costa, actualmente erosionada y basculada o levantada de manera diferencial, entre la Depresión Central y la Cordillera Principal. En efecto, estas tobas no se encuentran en los cauces de los valles actuales, pero sí aparecen colgadas o cortadas por el curso actual de los ríos, en la Cordillera Principal, o en borde de los relieves alrededor de la Depresión Central, en Santiago, o en la Cordillera de la Costa, en el área de Melipilla. La figura 3 muestra cómo pudo haberse conservado el paleorrelieve del Plioceno superior, anterior a los depósitos de tobas y al encajonamiento de la red hidrográfica actual (ríos Maipo, El Volcán, Yeso). Por ejemplo, el río Maipo tiene una altura de $700 \mathrm{~m}$ en Las Vizcachas, a la entrada de la cuenca de Santiago mientras que cerca de Isla de Maipo su altura es de 290 m. Las diferencias de altura entre el 'thalweg' del río principal (río Maipo) y la superficie sobre la cual se apoya la ignimbrita muestran que el alzamiento, en relación con el cauce del río y la erosión, no es regular. Esto implica que ciertas zonas se levantan o se erosionan más fácilmente que otras, posiblemente debido a movimientos relativos de bloques como desplazamientos verticales a lo largo de fallas discretas.

El análisis de las imágenes satelitales Landsat TM, Aster y los DEM SRTM 90 m (USGS) permiten establecer el patrón de los lineamientos principales que afectan la zona de estudio (Fig. 4) y determinar las posibles fallas principales. La tectónica tiene una influencia importante tanto en el trazado como en la evolución de los ríos, lo que se observa directamente en las rocas consolidadas, ya que los cursos de agua y las redes de drenaje siguen las líneas de debilidad mediante erosión diferencial. Por otra parte, los ríos reaccionan a los movimientos de la tectónica activa modificando o ajustando su curso (Schumm et al., 2000). El examen de la red fluvial muestra que la zona estudiada está caracterizada por tres tipos diferentes de drenaje (e.g., Howard, 1967) (Fig. 


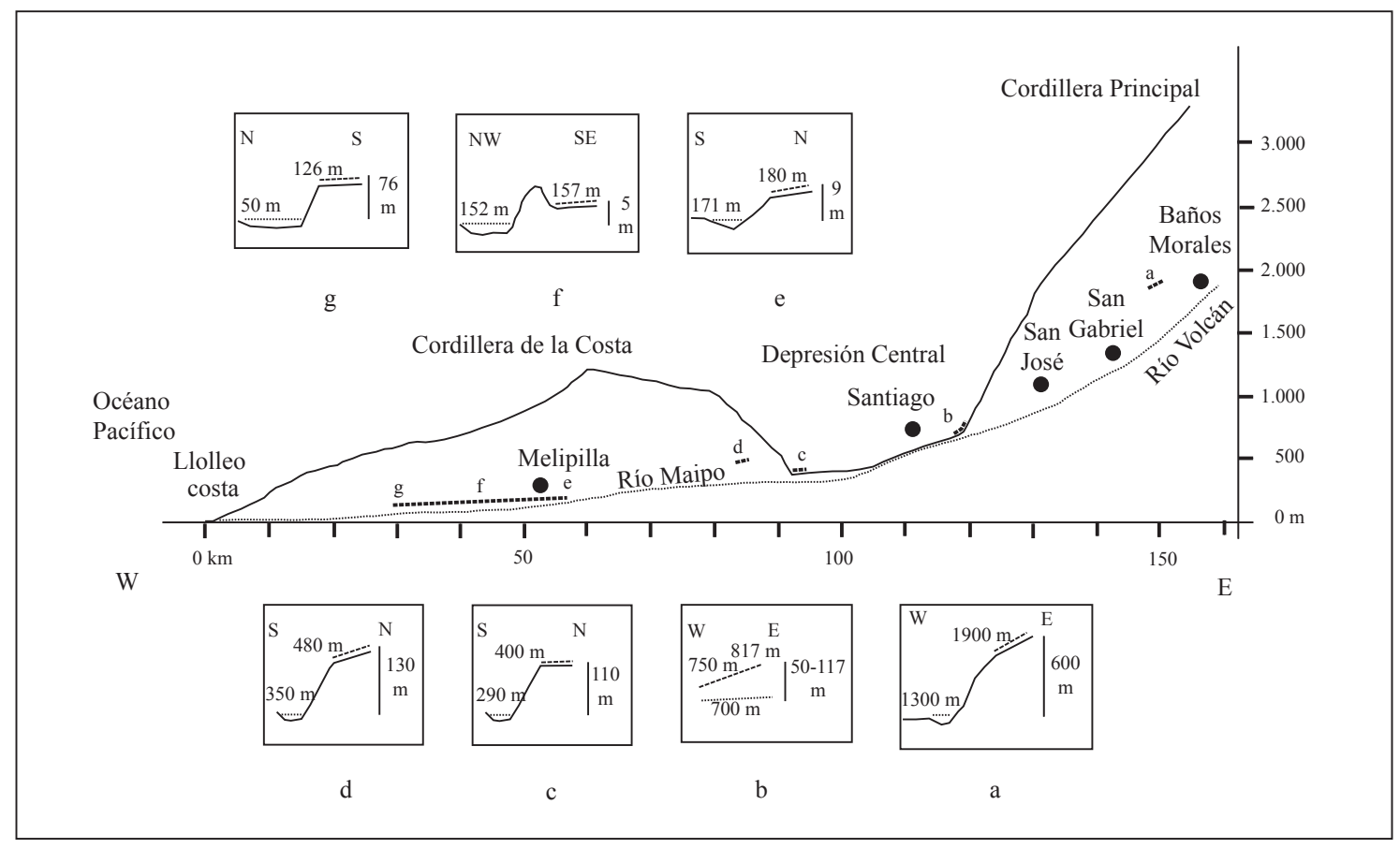

FIG. 2. Perfil de los ríos Volcán y Maipo y ubicación de los afloramientos de la superficie de base de las tobas y de la Ignimbrita Pudahuel. En los marcos 'a'-'g' se indica la altura de las tobas en relación con el lecho de los ríos con línea de trazos. Se nota el alzamiento de la Cordillera Principal y/o la erosión del río de la preferentemente de la cordillera Principal.

4): i) Drenaje dendrítico (de tipo roble) en la parte oeste de la red fluvial, al borde este de la cuenca de Santiago. Este se manifiesta por la existencia de sedimentos horizontales a subhorizontales, uniformemente resistentes, con una pendiente local débil; ii) Drenaje en malla, en la parte central más importante (Cordillera Principal). Este drenaje es característico en sedimentos fuertemente inclinados o plegados, a veces volcánicos o en rocas metasedimentarias de muy bajo grado, rocas intrusivas o zonas con fracturas paralelas. En este tipo de drenaje los pequeños ríos tributarios son prácticamente del mismo tamaño y se ubican a ambos lados de ríos más grandes, subsecuentes y paralelos; iii) Drenaje paralelo, en la parte este de la Cordillera Principal (lado argentino) y en la Cordillera Frontal. Los drenajes paralelos tienen dos direcciones: una NO-SE, al norte (extremidad sur de la Precordillera ) y otra E-O, al sur (extremidad norte de la Cordillera Frontal).

Tanto al oeste como al este (Cuenca de Santiago y vertiente oriental de la cordillera) la red hidrográfica (el drenaje) está directamente relacionada con la mor- fología de los terrenos. En cambio, en la parte central, la red está bajo la influencia del patrón estructural de la cadena en donde los cursos tienen las mismas direcciones que las fallas mayores y menores.

De acuerdo con Mackin (1948) todo río tiende a un perfil de equilibrio, el que será modificado de acuerdo con el cambio en los factores que controlan este curso de agua hacia una dirección que tenderá a disminuir y absorber el efecto del cambio. En la figura 2, se observa que la superficie de base de los depósitos de tobas corresponde a un antiguo perfil de equilibrio de los ríos Maipo y Volcán mientras que el perfil de equilibrio actual es diferente, ya que la Cordillera Principal ha sufrido un levantamiento mayor que la Cuenca de Santiago y la Cordillera de la Costa. Existe, por lo tanto, una zona crítica entre la Cuenca de Santiago o Depresión Central y la Cordillera Principal (Fig. 5) que puede corresponder a la Falla San Ramón-Apoquindo (Rauld, 2002; Ormeño, 2007). Pueden determinarse cuatro segmentos a lo largo del curso del río Maipo-Volcán (Fig. 2) [con uso del programa RiverTools, 3.02]. 


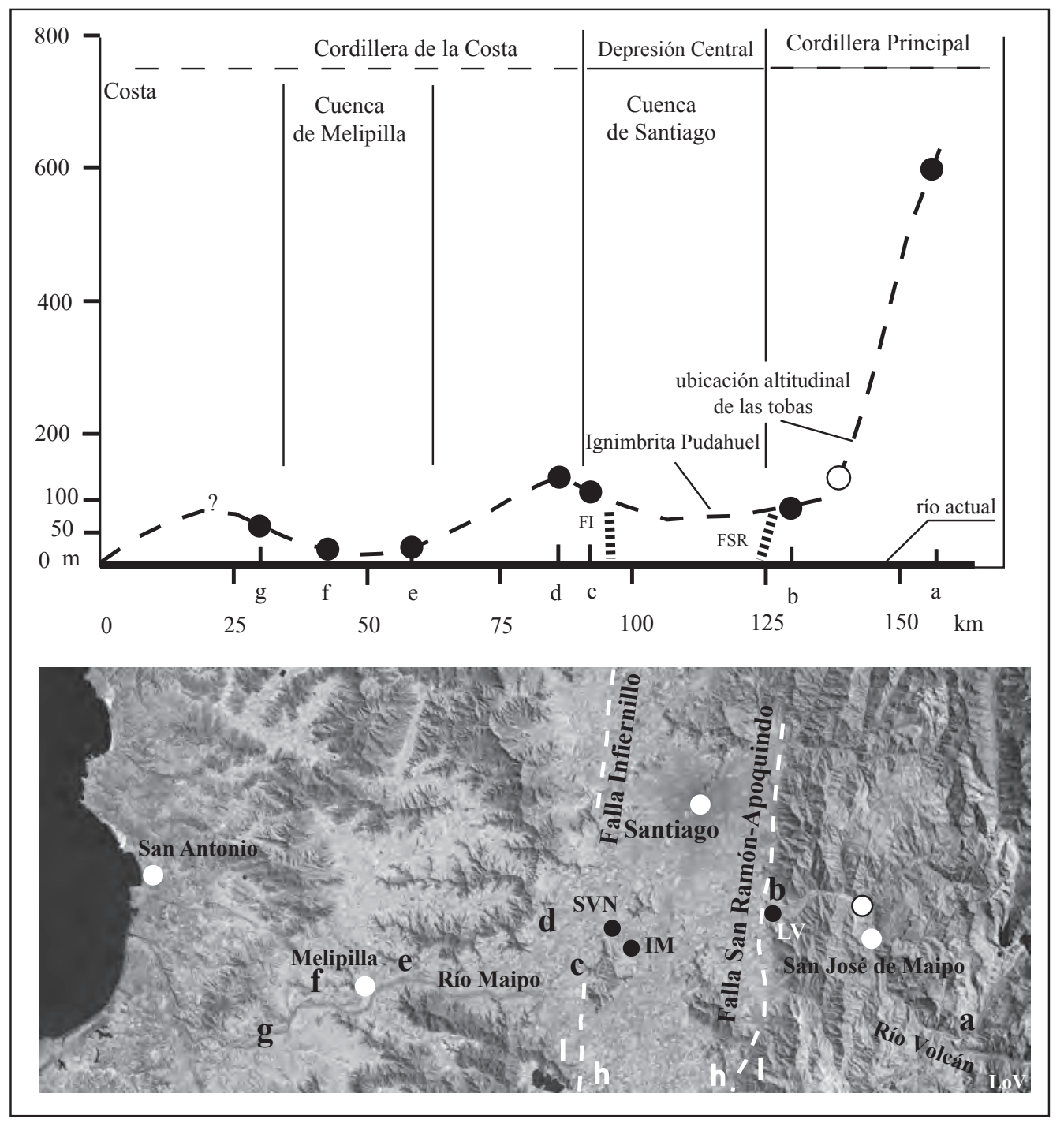

FIG. 3. Relación morfológica entre el lecho del río actual (Río Volcán más Río Maipo en la abscisa) y las tobas (incluyendo la Ignimbrita Pudahuel) con línea de trazos. FSR: Falla San Ramón-Apoquindo; FI: Falla Infiernillo; SVN: San Vicente de Naltagua; IM: Isla de Maipo; LV: Las Vizcachas; LoV: Lo Valdés. Si se considera con el lecho del río como nivel de referencia, se nota que las tobas no se ubican a la misma altura a lo largo del río. Se puede deducir un alzamiento importante de la Cordillera Principal con encajonamiento del 'thalweg', un alzamiento relativamente débil de la Cordillera de la Costa en la cual la cuenca de Melipilla se comporta como una zona en hundimiento relativo, lo cual se observa también en la Depresión Central, representada aquí por la Cuenca de Santiago. 'a'-'g': explicación en figura 2.

FIG. 4. Modelo de elevación digital de la zona ubicada entre Santiago, Chile y Argentina (arriba); Orientación de los principales lineamientos en relación a la red hidrográfica (abajo). Las principales direcciones son ESE-ONO, ENE-OSO y N-S. El cuadro blanco (arriba) y negro (abajo), indica el sitio de mediciones de La Cantera. Interpretación morfológica de los diferentes tipos de drenaje en relación con la altitud, la naturaleza de las rocas y las pendientes en la Cordillera Principal entre Santiago y Argentina. 1. principales lineamientos; 2. límites de las diferentes zonas morfológicas en relación al tipo de drenaje (A. Depresión Central; B. Cordillera Principal, con línea divisoria de agua; C. Cordillera Principal, vertiente oriental argentina); 3. línea divisoria de agua; 4. drenaje dendrítico (en zona A, característico de una pendiente débil de tipo monoclinal en depósitos horizontales uniformemente resistentes); 5. drenaje en malla (en zona B, característico de una zona de alta montaña con rocas sedimentarias inclinadas o plegadas, rocas volcánicas o metamórficas de bajo grado, o con fracturación paralela ); 6. drenaje paralelo (en zona C, característico de una pendiente moderada, con formas de terreno subparalelas). CP: cerro del Plomo; VT: volcán Tupungato. Explicación en el texto. 


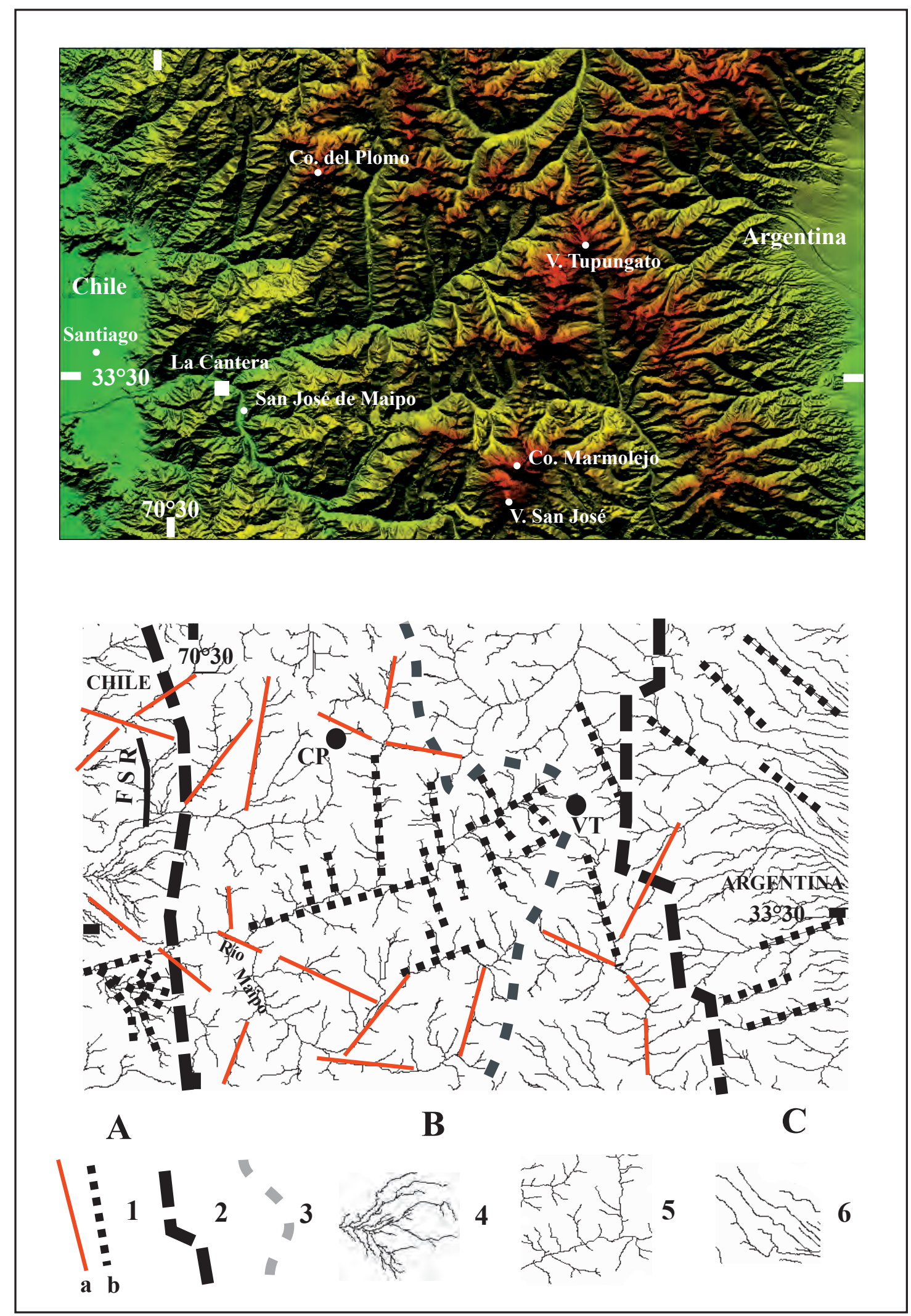


Entre los puntos a y $\mathbf{b}$, la Cordillera ha sufrido un levantamiento notable y el curso de agua se encajonó bastante $(600 \mathrm{~m})$; entre b y e el encajonamiento es menor pero siempre bien marcado (100 m), lo que permite inferir que la Cordillera de la Costa se ha levantado menos o más lentamente en relación con la Cordillera Principal; entre e y g el levantamiento es menor lo cual señala que este bloque de la Cordillera de la Costa no está levantado y, posiblemente, esté hundido con respecto al resto de la Cordillera de la Costa. Por último, entre g y la desembocadura del río, en el Océano Pacífico, el levantamiento es nuevamente mayor del orden de $76 \mathrm{~m}$. De hecho, a lo largo de la costa se observa que las terrazas marinas cuaternarias están también alzadas. Además, en la figura 5, aparece un cierto número de umbrales o anomalías en el curso de los ríos Volcán y Maipo que corresponden a indicadores de deformación tectónica reciente e.g., fallas.

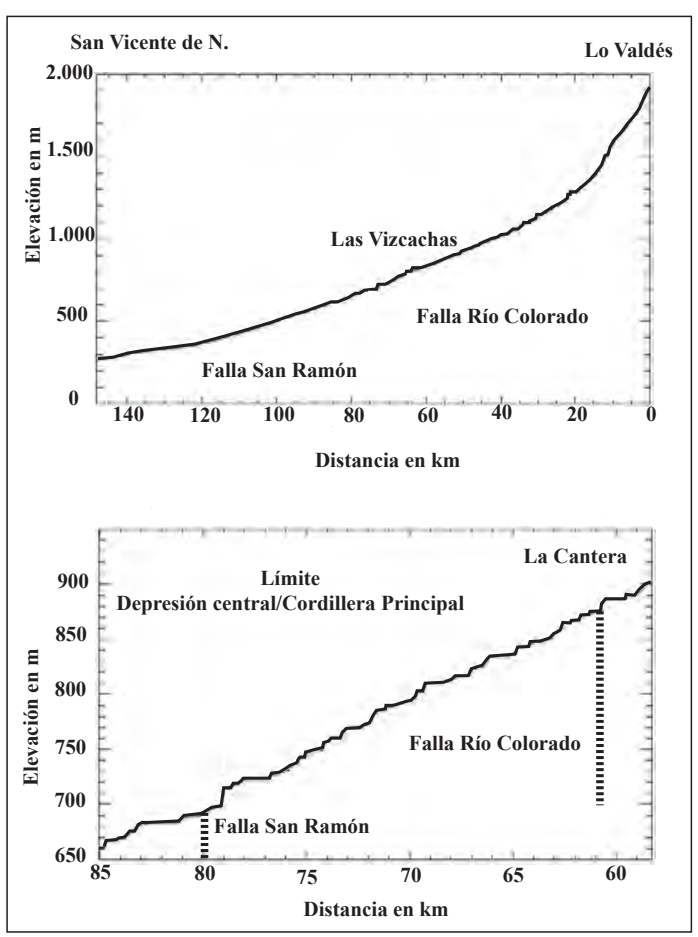

FIG. 5. Relación entre zonas de falla, morfología y perfil del río Maipo en el límite Cordillera Principal/Depresión Central, entre Lo Valdés y San Vicente de Naltagua (cf. Fig. 3) y abajo, con detalle, entre La Cantera y la Falla San Ramón. Se notan cambios de pendiente en el curso del río, pasando por las zonas de la Falla Río Colorado y de la Falla San Ramón, al SE de Santiago.

\section{Las terrazas del río Maipo}

\subsection{Descripción geomorfológica}

En la ribera izquierda (o ribera sur) del valle del río Maipo, al sur de la confluencia del río Colorado con el río Maipo, las terrazas fluviales se apoyan sobre un sustrato constituido por rocas de la Formación Abanico.

El mapeo de estas terrazas (Figs. 6 y 7) a lo largo del río Maipo, entre El Manzano y San José de Maipo, permite identificar cinco niveles principales, además del lecho actual. En la confluencia de los ríos Colorado y Maipo, cerca de una antigua cantera de ripios, esos niveles de terraza se ubican respectivamente a: $\mathrm{t} 0=880 \mathrm{~m}$ de altura, $\mathrm{t} 1=881 / 884 \mathrm{~m}, \mathrm{t} 2=896$ $\mathrm{m}, \mathrm{t} 3=920 / 925 \mathrm{~m}, \mathrm{t} 4=950 \mathrm{~m}$ y t $5=1.000 / 1.050 \mathrm{~m}$.

El nivel to corresponde al 'thalweg' o lecho menor del río actual, equivalente al nivel de estiaje, coincidente con el trazado del río en el mapa a escala 1:50.000 (IGM). La confluencia de los ríos Maipo y Colorado se estima en $880 \mathrm{~m}$ s.n.m. La sedimentación actual se limita a bancos de material grueso y escasa arena, caracterizando un régimen fluvial torrencial.

La terraza t1 está muy reducida debido a la fuerte erosión actual del río en estación de lluvias (invierno) y corresponde a algunos depósitos ubicados a menos de 1 o $2 \mathrm{~m}$ por sobre el cauce actual. Sobre ella, se desarrolla un poco de vegetación, pero durante las crecidas es cubierta por las aguas del río y actúa como una llanura de inundación.

La terraza t 2 está mejor desarrollada y se ubica a una altura de $896 \mathrm{~m}$ (punto de nivelación) siempre por debajo de la curva de nivel $900 \mathrm{~m}$. Esta terraza se encuentra alrededor de $15 \mathrm{~m}$ por encima de t0; sobre ella crecen arbustos y árboles y no la alcanzan las crecidas normales de invierno. El puente de ferrocarril se encuentra sobre esta terraza.

La terraza $\mathbf{t} 3$ está muy desarrollada en ambas riberas del río (920 $\mathrm{m}$ de altura y $40 \mathrm{~m}$ encima de t0), sobre todo en la ribera derecha (aquí ribera norte) donde se ubica el pueblo de El Manzano. En la zona de estudio, esta terraza se desarrolla sobre $4,5 \mathrm{~km}$ de largo y con un ancho de 500 a $800 \mathrm{~m}$. En ella se han instalado los pueblos y su superficie está ocupada por campos y cultivos. El puente del camino de vehículos está al nivel de esta terraza t3.

La terraza $\mathbf{t} 4$ está muy pobremente expuesta y presenta únicamente remanentes de su superficie en el sector estudiado. Está constituida por conglo- 


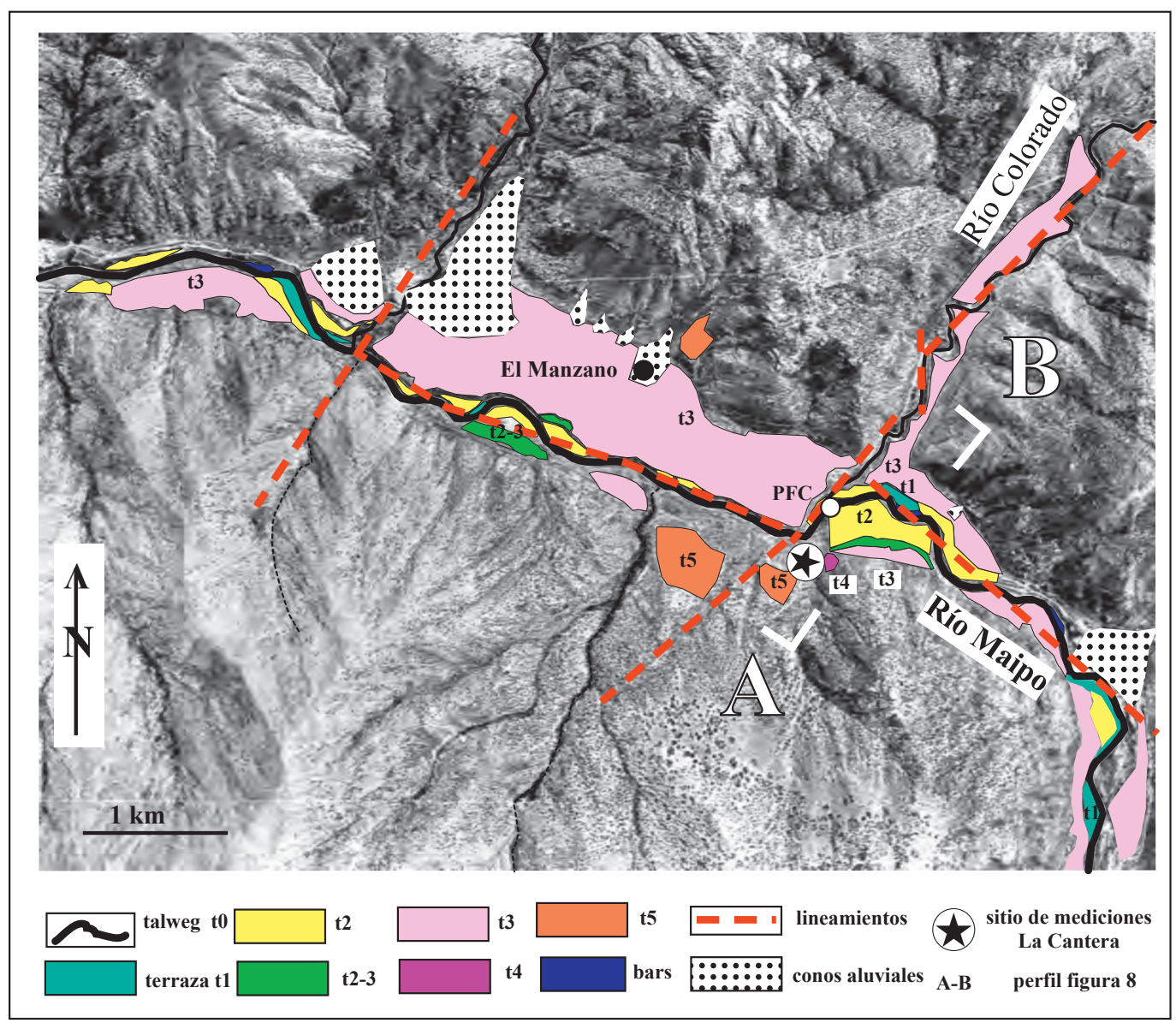

FIG. 6. Mapa de las terrazas aluviales en la zona de El Manzano/Río Colorado. Interpretación geológica esquemática de una fotografía aérea (IGM-HY 4061) con ubicación del sitio de mediciones La Cantera (estrella negra). PFC: Puente del ferrocarril. t0 a t5 representan la superficie de las terrazas aluviales escalonadas, de la más joven a la más antigua.

merados y se ubica a unos $950 \mathrm{~m}$ de altura, $70 \mathrm{~m}$ encima de la terraza t0.

Por último, la terraza $\mathbf{5} 5$ presenta un interés primordial pues es la única en la cual hay evidencias de deformación tectónicay, por lo tanto, se describe con mayor detalle. Unos $500 \mathrm{~m}$ al sur de la confluencia de los ríos Maipo y Colorado, los remanentes de esta terraza no presentan una superficie plana muy desarrollada, pero presentan un corte en sedimentos fluviales, apoyándose y descansando sobre paleorrelieves de brecha volcánica de la Formación Abanico. Los sedimentos más altos de la terraza alcanzan una altura de 1.050 a $1.060 \mathrm{~m}, 170$ a $180 \mathrm{~m}$ por encima del nivel t0. Su espesor expuesto no sobrepasa los 20 m (Fig. 8) y está constituida por depósitos de gravas arenosas y arenas interestratificadas con in- tercalaciones limo-arcillosas, por flujos de barro de tipo 'debris flows' (banco de base del perfil que se ve en el afloramiento) típicos con grandes clastos, de 1 a $100 \mathrm{~cm}$ de diámetro, 'flotando' en la parte alta del banco (conglomerados matriz soportados). En estos sedimentos de tipo flujo de barro, con clastos mal seleccionados, subangulosos y con arreglo caótico, no se pudo determinar el sentido de la corriente que los depositó. En la parte de arriba del depósito, el registro sedimentario sugiere un régimen fluvial más tranquilo en que los depósitos están constituidos por bancos de arena fina no consolidada, con laminación planar, entre los cuales se encuentran lentes de conglomerado y paleocanales. Existe una cierta imbricación de los clastos lo que sugiere un régimen de flujo constante. Ciertas imbricaciones indican un 


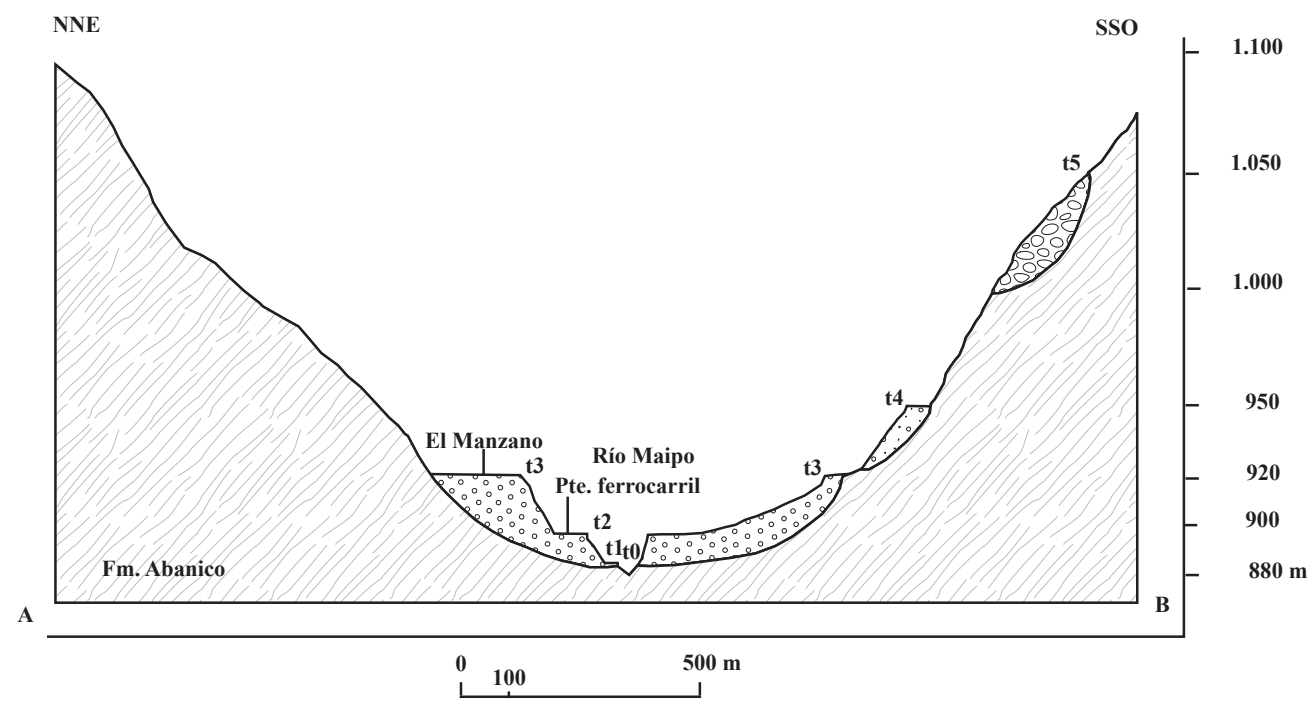

FIG. 7. Perfil de las terrazas aluviales al sur del pueblo El Manzano. El cauce del río, o nivel t0, se encuentra en el substrato de la Formación Abanico. Las terrazas t1 a t3 se encajonan en un mismo depósito aluvial. Los escasos remanentes de la t4 se encuentran colgados en el flanco sur del valle y son depósitos más antiguos que t3. Ocurre lo mismo con t5, más antigua y con depósitos más heterogéneos y gruesos todavía.

sentido aproximado de la corriente, pero aparentemente mayoritario de SE a NO, lo que permite pensar que estos depósitos pertenecen más bien al curso del río Maipo y no al del río Colorado, ya que en este último caso la corriente debería ser dirigida hacia el SO. La falta de un número suficiente de datos del sentido de la corriente no permite establecer estadísticamente su dirección precisa. Sin embargo, se sabe que en régimen de tipo ríos anastomosados, el sentido de la corriente es muy variable. En la base de los niveles finos, existe un depósito cinerítico blanco, sin datación disponible, bajo forma de un material retrabajado.

No fue posible determinar exactamente la edad del sistema de terrazas por falta de indicadores; sin embargo, su edad máxima podría ser pleistocena inferior dado que la más antigua (t5) contendría en su base una capa de ceniza, la cual podría corresponder a la 'Unidad Cuaternaria Joven' de Rauld (2002).

\subsection{Estructuras}

Las observaciones de fallas se hicieron en tres sitios (Fig. 1): 1. en el sitio denominado La Cantera, en los depósitos de la terraza t5, 2. a unos $350 \mathrm{~m}$ más al NO del primer sitio, en el borde de la carretera, en las rocas de la Formación Abanico, unos 100 m por debajo del afloramiento de $t 5$, y 3. a unos 25 km al ENE, en las rocas del Plutón La Gloria, en la confluencia de los ríos Colorado y Olivares, cerca de Alfalfal. En tanto, el análisis de la deformación en los afloramientos de la Formación Abanico y del Plutón La Gloria se hizo de manera 'clásica' y no presentó ninguna dificultad; sin embargo, el análisis de la deformación en los depósitos no consolidados o mal consolidados de la terraza 15 necesitó más atención.

En esta terraza alta 5 (Fig. 9), se observan fallas inversas con manteo al norte y cuyo rechazo vertical es centimétrico a métrico. En este afloramiento (UTM: 0372553/6281708), el rechazo acumulado máximo alcanza $11 \mathrm{~m}$. En las capas relativamente duras, como conglomerados o arenas consolidadas, las fallas se desarrollan por varios metros y a veces son cortadas por depósitos discordantes. Los pliegues de arrastre ('drag-folds') (Fig. 10, fotografías 1 y 2), ligados al movimiento de las fallas, están bien marcados en las capas blandas, pero tanto el fracturamiento como el plegamiento se produjeron cuando las capas estaban suficientemente litificadas. No se trata entonces de la deformación de un flujo lodoso viscoso durante su propia sedimentación, en cuyo caso se encontrarían pliegues de flujo, de tipo 'slump'. Además, los niveles de arena, indicios de una sedimentación más tranquila, se encuentran involucrados en esos pliegues, lo que excluye un posible plegamiento durante la sedimentación. Tampoco 
se trata de un fracturamiento en sedimento blando, acuoso, en estado de depositación (no hay 'slumps'). Se descarta también un deslizamiento; las capas no están desorganizadas. En varios puntos, a lo largo de los planos de falla y dentro de los pliegues de arrastre, los cantos planos y alargados, conservan su eje de alargamiento en posición paralela a las bases de los bancos, o sea, a la estratificación.

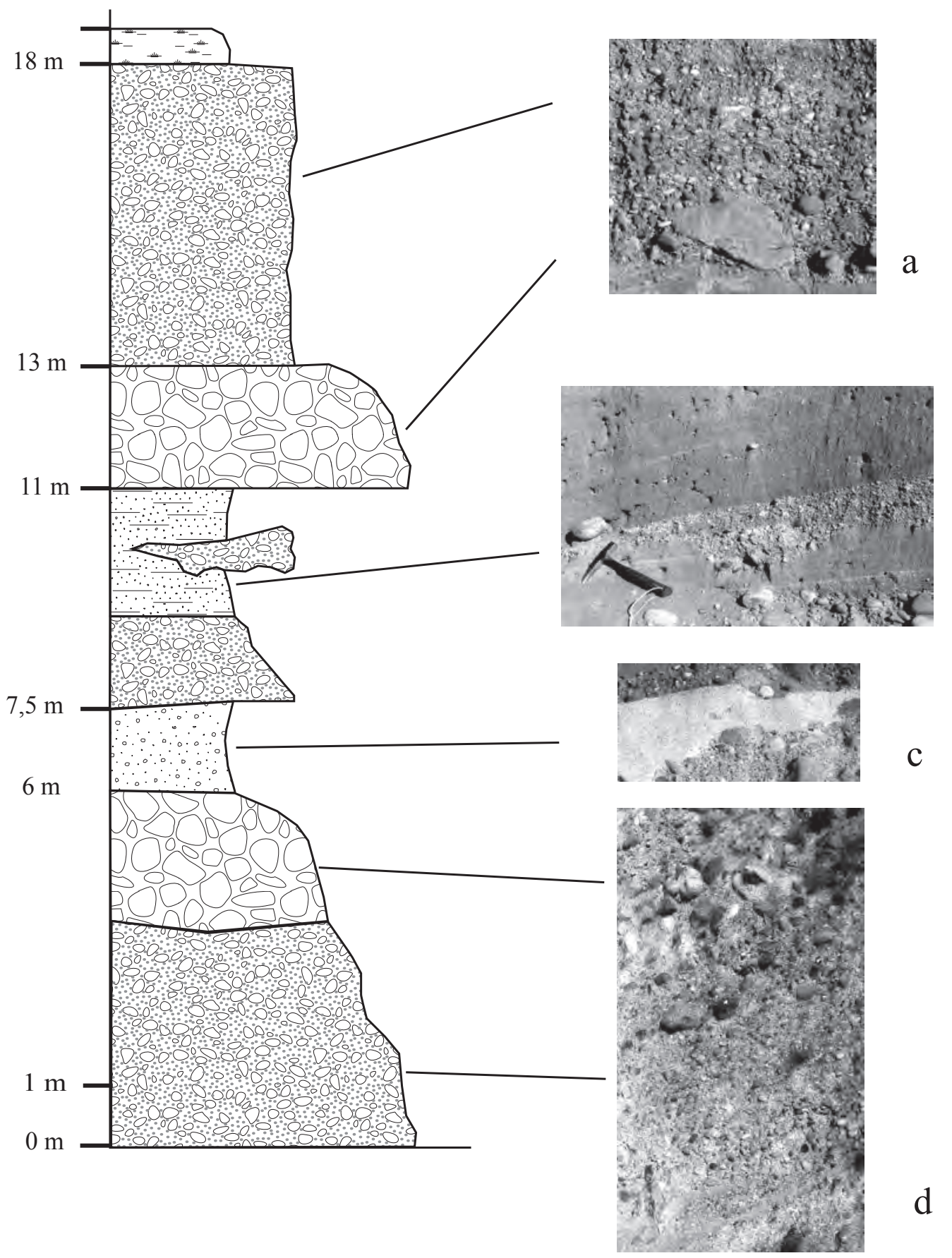

FIG. 8. Columna estratigráfica esquemática de la alta terraza t5 e ilustración de las facies de los diferentes tipos de depósitos. a. depósito de flujo de detritos; b. arena con lentes de gravas; c. toba removilizada (?); d. depósitos fluviales gruesos. 


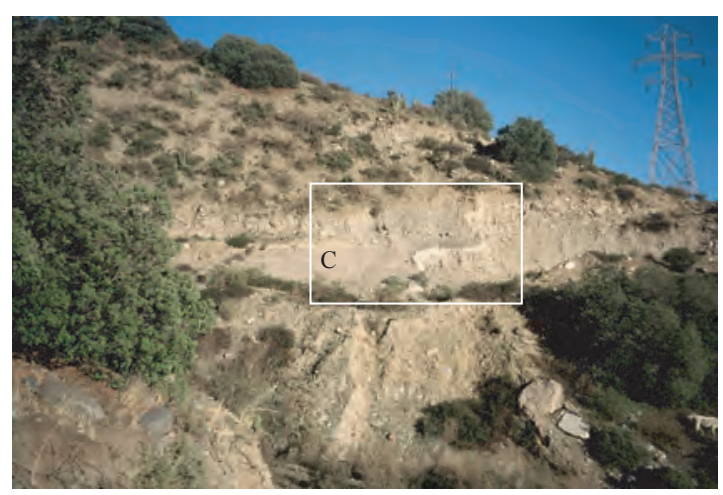

A

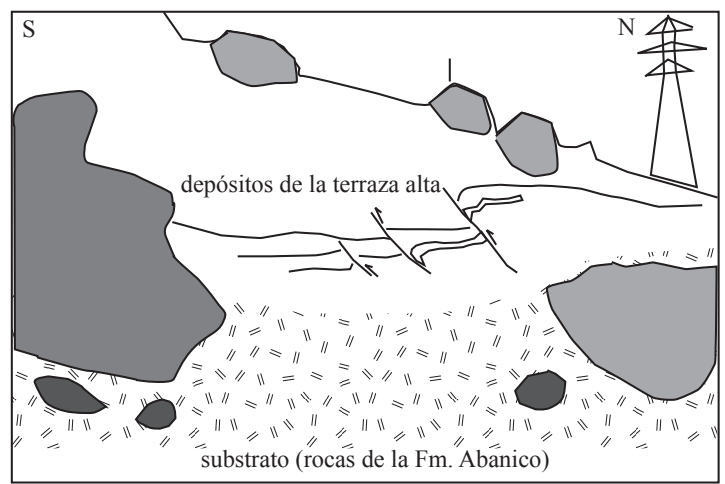

B

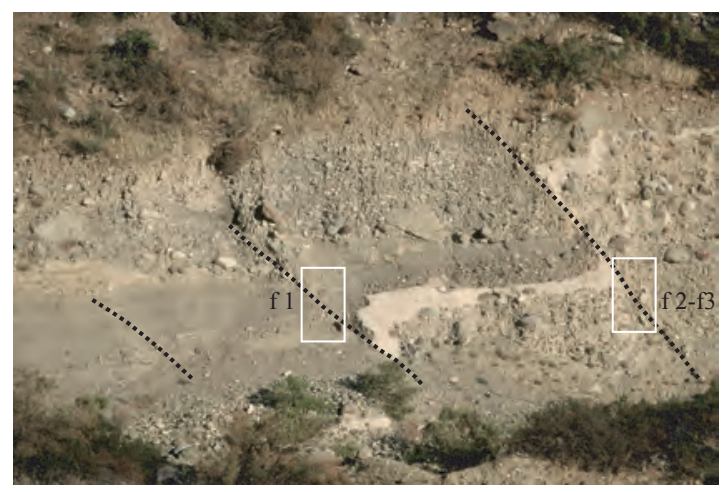

$\mathrm{C}$

FIG. 9. La Cantera, en el valle del río Maipo. A. aspecto del afloramiento de los depósitos fallados y plegados de la terraza alta t5, descansando sobre las rocas de la Formación Abanico, cubierta aquí por coluvios. El frente de la cantera tiene una orientación próxima a N-S; B. interpretación de la fotografía A; C. ubicación de las fotografías f1, f2 y f3 de la figura 10 (fotografías tomadas de Cembrano et al., 2007). La falla inversa sinistral de la fotografía 1 es $\mathrm{N} 60^{\circ} \mathrm{E} 59^{\circ} \mathrm{N}$ 'pitch' $74^{\circ} \mathrm{O}$. La falla inversa de las fotografías 2 y 3 es $\mathrm{N} 100^{\circ} \mathrm{E} 58^{\circ} \mathrm{N}$ 'pitch' $63^{\circ} \mathrm{O}$ y, presenta cantos estriados. En la parte alta de la fotografía C, se nota que ciertas fallas están cortadas por depósitos posteriores. En este afloramiento, no se observan planos de falla cortando la Formación Abanico, pues está cubierta por coluvios. Fotografías tomadas mirando hacia el oeste.

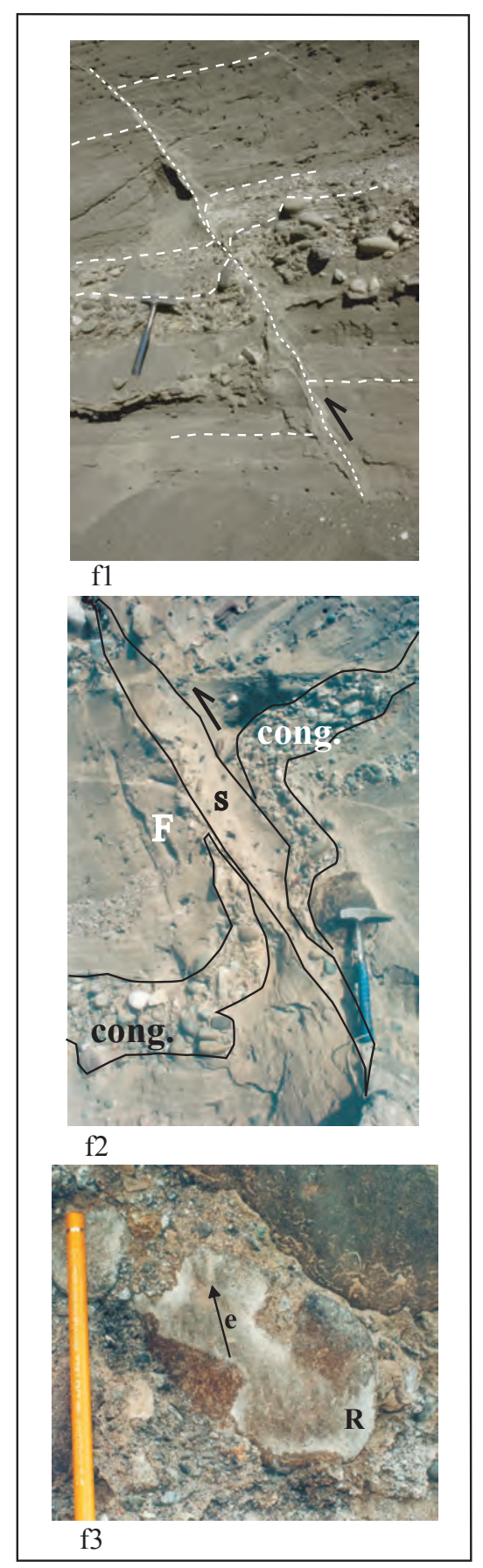

FIG. 10. Fotografías de los tipos de deformación encontrados en este afloramiento de La Cantera. f1. falla inversa de rechazo decimétrico (fotografía tomada de Cembrano et $a l ., 2007) ; \mathbf{f}$. falla inversa (F) con pliegue de arrastre en el conglomerado (cong.), formación de una salbanda de arena (s) en el plano de falla F; f3. detalle de un canto rodado ( $\mathrm{R}$ ) estriado (e) involucrado en los pliegues de arrastre (plano de estriación: falla inversa dextral $\mathrm{N} 100^{\circ} \mathrm{E} 60^{\circ} \mathrm{N}$ pitch $64^{\circ} \mathrm{O}$ ); la flecha indica el sentido inverso del movimiento del bloque superior. 
El análisis de la fracturación se hizo a partir tanto del estudio de los planos de falla que separan verticalmente las capas y la observación de indicadores cinemáticos sobre las superficies de los cantos en los conglomerados (e.g., Petit, 1987; Doblas, 1998; Doblas et al., 1997; Ruano y Galindo-Zaldívar, 2004). La particularidad de los cantos de un conglomerado es que ellos tienen una superficie lisa debida al transporte fluvial, de modo que estas superficies pueden registrar pequeños movimientos que a veces no se marcan sobre superficies de fallas más rugosas. Cantos deformados pueden tener un flanco en el plano de falla o encontrarse dentro del espesor de la falla o su salbanda, y el efecto de la estriación será máximo. En los fragmentos de los conglomerados deformados, las diferentes estructuras pueden resultar del contraste entre las propiedades mecánicas existentes entre los cantos y la matriz. Las fallas que cortan tanto la matriz como los cantos indican un comportamiento frágil del conjunto. Hippolyte (2001) señala que en los conglomerados poco cementados y deformados por cizalle, el contraste entre los módulos elásticos de los cantos y de la matriz (a la cual se añade la adherencia canto/matriz, McEwen, 1981), resulta en una deformación esencialmente localizada al límite canto/matriz. En conglomerados, estas superficies estriadas son los vestigios de la deformación tectónica, en donde las estrías corresponden al desarrollo de superficies de cizalle. Las fallas que cortan un conglomerado pueden desarrollar numerosas superficies de cizalle que son comparables a la propagación de fallas en un material prefracturado (Hippolyte, 2001). Petit et al. (1985) y Doblas et al. (1997) señalan que los cantos estriados pueden ser utilizados para determinar los paleoesfuerzos de manera equivalente a los planos de fallas en donde estas superficies son analizadas como microfallas. En el caso estudiado de la terraza t5 tanto la regularidad de la estriación en cada canto como el paralelismo entre las direcciones de estrías sobre ellos y el mismo sentido de desplazamiento producido por las fallas, permiten concluir que esta deformación es típicamente tectónica (Fig. 10, fotografía 3). En los diagramas de la figura 11 se analiza el sentido del movimiento, en este caso, es inverso. Este fue determinado por figuras de detención de elementos estriadores en la superficie de los cantos. No hemos encontrado cantos fracturados lo que es consistente con una deformación muy superficial (Eidelman y Reches, 1992).

\section{Datos de fallas, estrías e indicadores cinemá- ticos}

La deformación de la terraza alta del río Maipo había sido descrita de manera breve (Lavenu et al., 1994; Lavenu et al., 2000, Lavenu, 2006a) bajo el nombre de Falla de San José de Maipo. Su análisis tectónico indicaba una dirección de acortamiento aproximadamente N-S. Aquí examinamos con más detalle estas estructuras.

\subsection{Mediciones en La Cantera}

En el frente de esta antigua cantera, en los sedimentos de la terraza $\mathrm{t} 5$, se midieron nueve planos de falla, directamente en el plano de falla o sobre cantos de conglomerados en la zona de falla. Las orientaciones de las fallas están comprendidas entre $\mathrm{N} 30^{\circ} \mathrm{E}$ y $\mathrm{N} 135^{\circ} \mathrm{E}$, la mayoría con manteo al norte. Este grupo de fallas se caracteriza por tener dos direcciones principales: una ENE-OSO, paralela al lineamiento seguido por la traza del río Colorado y la segunda ESE-ONO, paralela al río Maipo, en este tramo. Los ejes de pliegues de arrastre asociados a las fallas son paralelos entre sí y tienen aproximadamente una dirección NE-SO, subhorizontal $\left(\mathrm{N} 42^{\circ} \mathrm{E}\right.$ a $\left.\mathrm{N} 51^{\circ} \mathrm{E}\right)$. Tales observaciones confirman una vez más el carácter tectónico de una deformación en compresión.

\subsection{Mediciones en el sustrato de la terraza}

La terraza $t 5$ descansa sobre sedimentos muy fracturados de la Formación Abanico. Estos sedimentos tienen un ligero manteo hacia el oeste. En esta unidad, en capas de toba y brecha volcánica ubicadas a unos $200 \mathrm{~m}$ del afloramiento cuaternario, en el borde del camino asfaltado, se midieron 38 planos de fallas, todos ellos estriados. Esas fallas son inversas $(87 \%)$, subparalelas a las dos direcciones de los lineamientos característicos de la zona, ENEOSO y ESE-ONO (Fig. 4).

\subsection{Mediciones en las rocas intrusivas del Plutón La Gloria}

A unos $25 \mathrm{~km}$ al NE de la confluencia del río Colorado con el río Maipo, más allá de la planta hidroeléctrica El Alfalfal, en la confluencia de los ríos Colorado y Olivares (Fig. 1) un afloramiento 

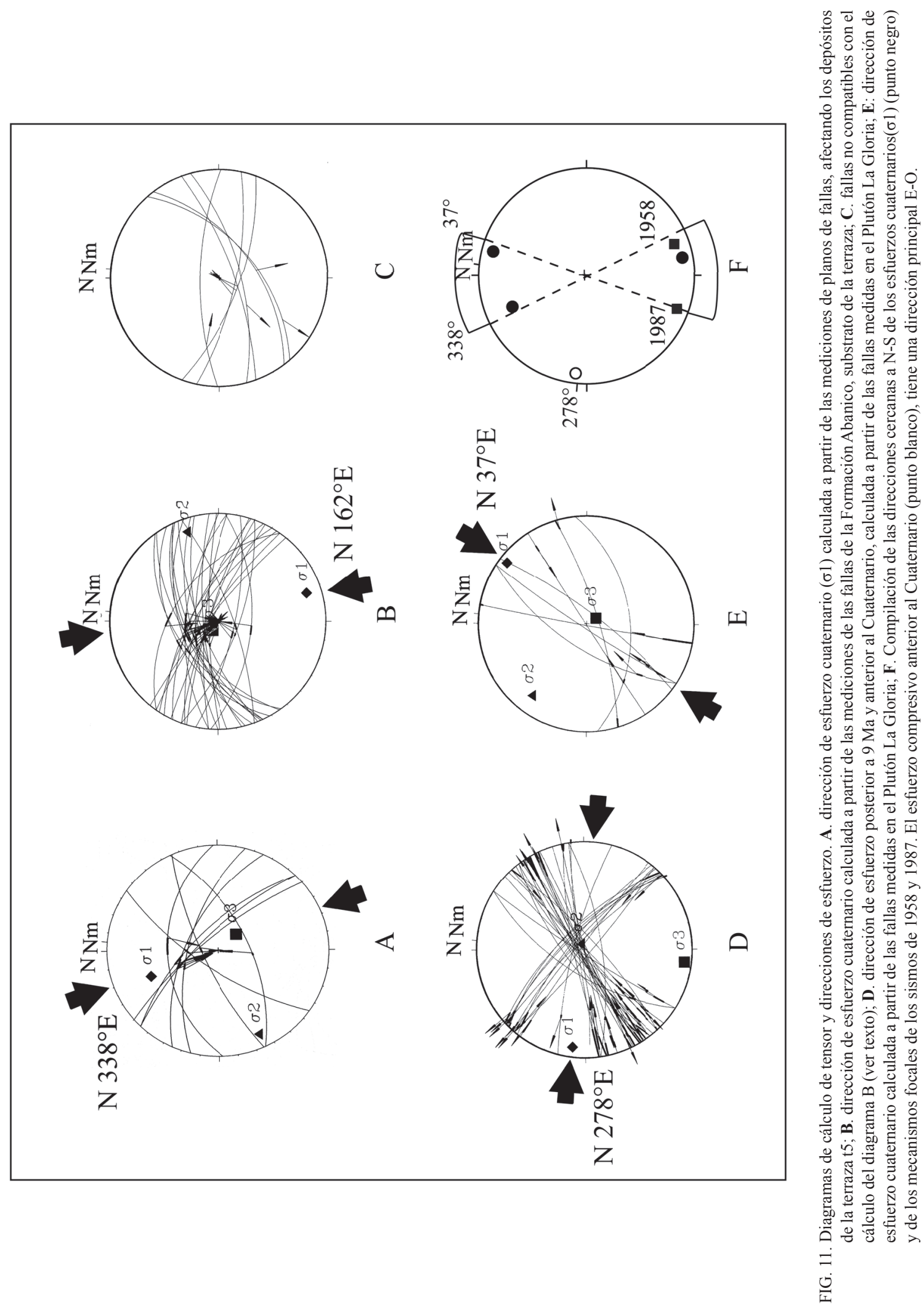
de granodiorita (Plutón La Gloria, 9 Ma; Cornejo, 1991) intruye a la Formación Farellones. Este plutón se encuentra en la intersección de dos lineamientos: uno, el más importante, de dirección ENE-OSO que corresponde al curso del río Colorado; otro, menor, y de dirección ESE-ONO. En este intrusivo se midieron 47 fallas de rumbo.

\section{Interpretación cinemática de los datos de fallas y estrías}

\subsection{Depósitos de la terraza 15}

La presencia de estrías sobre los planos de falla o sobre los cantos rodados cercanos a los planos de fallas, confirma el carácter tectónico postsedimentación de la deformación. Los cantos involucrados en los pliegues de arrastre de falla conservan su organización de depositación y se orientan según el plegamiento, hasta verticales, lo que confirma una vez más el carácter litificado de los sedimentos. Un cálculo de inversión de los datos de fallas y estrías permite determinar la dirección de $\sigma 1\left(\mathrm{~N} 338^{\circ} \mathrm{E}\right)$, $\sigma 2\left(\mathrm{~N} 242^{\circ} \mathrm{E}\right)$ ambos subhorizontales y $\sigma 3$ vertical (Fig. 11-A). Esta dirección principal de compresión es casi paralela al eje de acortamiento máximo $\mathrm{Z}=\mathrm{N} 136^{\circ} \mathrm{E}$, deducida de los ejes de pliegues de arrastre de falla medidos directamente en terreno, en los depósitos de t5.

\subsection{Sustrato de la terraza $t 5$}

De los 38 planos medidos, 31 son compatibles con un evento tectónico compresivo de dirección cercana a N-S $\left(\sigma 1=\mathrm{N} 355^{\circ} \mathrm{E}\right)$ (Fig. 11-B). Esta dirección de compresión es muy cercana a la encontrada en los sedimentos cuaternarios suprayacentes, con solamente $17^{\circ}$ de diferencia, lo que apoya la hipótesis de una compresión tectónica cuaternaria que habría afectado tanto al sustrato prefracturado como a los depósitos de la terraza. Estas 31 fallas son reactivadas por la tectónica cuaternaria y las pocas fallas restantes (siete fallas inversas, normales y de rumbo) no son compatibles con ningún régimen tectónico común y podrían ser, en parte, el resultado de rotación de bloques por deslizamientos posteriores a t5 y debido a la erosión del valle del río, localmente de dirección E-O (Fig. 11-C).

\subsection{El Plutón La Gloria}

El análisis de las diferentes fallas permite concluir que hubo superposición de dos eventos tectónicos compresivos, uno bien nítido, con muchas fallas, de dirección principal $\sigma 1=\mathrm{N} 278^{\circ} \mathrm{E}$ (Fig. 11-D) y otro más discreto, con menos fallas y de dirección $\sigma 1=\mathrm{N} 037^{\circ} \mathrm{E}$ (Fig. 11-E). Esta última dirección $\left(\mathrm{N} 037^{\circ} \mathrm{E}\right)$ sería consistente con las direcciones de compresión encontradas en los depósitos cuaternarios de la terraza t5 (N $\left.338^{\circ} \mathrm{E}\right)$ o en la Formación Abanico $\left(\mathrm{N} 355^{\circ} \mathrm{E}\right)$.

Es posible concluir que en la zona de estudio existen dos eventos tectónicos compresivos sucesivos, el primero de dirección ol cercana a E-O, posterior a $9 \mathrm{Ma}$ y anterior al Cuaternario y el segundo de dirección $\sigma 1$ cercana a N-S y de edad cuaternaria (Fig. 11-F).

Esta argumentación es consistente con los estudios de microtectónica hechos hasta ahora en la región de Chile central, que han mostrado únicamente la existencia de sólo dos eventos de compresión neógenos. El primer evento tiene una dirección E-O que se extiende por toda la cordillera, pero se encuentra particularmente en la zona de Santiago (entre los $33^{\circ}$ y $37^{\circ} \mathrm{S}$ ), con una edad de 4,5-2,8 Ma; más al sur, entre los $37^{\circ}$ y $42^{\circ} \mathrm{S}$, su edad oscila entre los 8,4 y 3,6 Ma y por último entre los $42^{\circ}$ y $46^{\circ} \mathrm{S}$, muestra una edad de 5,4-1,6 Ma. Este evento compresivo de edad pliocena se observa también en otras partes de la Cordillera de los Andes (Lavenu, 2006a).

El segundo evento, de dirección N-S a NNE-SSO, es más discreto, pero se encuentra a lo ancho de todo Chile central, en la zona de estudio, en la Costa, en la Depresión Central y en la Cordillera Principal, con una edad posterior a 2,8 Ma. Se encuentra también más al sur entre $37^{\circ}$ y $42^{\circ} \mathrm{S}$ y con edad de menos de $3,6 \mathrm{Ma}$ y aún más al sur $\left(42^{\circ}-47^{\circ} \mathrm{S}\right)$ posteriormente a 1,6 Ma (Lavenu y Cembrano, 1999a).

Sin conocimiento de un episodio de deformación demostrado hasta ahora entre estos dos eventos tectónicos, se puede concluir que esta deformación corresponde a una dirección de esfuerzo N-S encontrado tanto en la Formación Abanico como en el Plutón La Gloria y pertenece al Cuaternario. La principal evidencia para concluir que el acortamiento N-S es cuaternario viene del hecho que corta las terrazas fluviales del río Maipo. 


\section{Discusión}

\subsection{Deformación cuaternaria versus sismicidad}

Establecer la naturaleza de la vinculación entre deformación de largo plazo y la sismicidad actual de una región de la corteza terrestre es un objetivo complejo. Los estudios de sismicidad cortical superficial conducidos en Chile central (e.g., Lomnitz, 1961; Barrientos y Eisenberg, 1988; Pardo et al., 2004; Salazar, 2005; Pardo et al., 2006) no permiten todavía obtener un patrón bien nítido de la geometría y cinemática de las fallas activas. El sismo cortical del 4 de septiembre de 1958 de Las Melosas (Lomnitz, 1961) activó una falla sinistral subvertical $\left(\mathrm{N} 13^{\circ} \mathrm{E} / 77^{\circ} \mathrm{O}\right)$, resultando de una dirección de compresión pobremente determinada, cercana a N-S. Más al sur, el sismo del 13 de septiembre de 1987 de Los Cipreses (<de $20 \mathrm{~km}$ de profundidad) reactivó una falla que Barrientos y Eisenberg (1988) caracterizan como una falla de dirección $\mathrm{N} 27^{\circ} \mathrm{E}$, de manteo $58^{\circ}$ y con un desplazamiento dextral que se sitúa casi por completo en el rumbo ('pitch' $=176^{\circ}$ ). Este movimiento tiene que resultar de un acortamiento NNE-SSO y no E-O (Barrientos et al., 2004). En este último caso, se necesitaría un vector de deslizamiento cercano a $90^{\circ}$ (deslizamiento en el manteo). Estos dos sismos, que corresponden a una deformación instantánea, parecen coherentes con la dirección de compresión deducida de las deformaciones cuaternarias de largo plazo (Fig. 11F) y, por lo tanto, estas deformaciones, cinemáticamente compatibles, podrían ser consideradas como cosísmicas de eventos sísmicos antiguos.

Más recientemente, Salazar (2005) y Pardo et al. (2006) muestran que la sismicidad superficial en la Cordillera Principal de Chile central, al norte de los $34^{\circ} \mathrm{S}$, se debe a un acortamiento E-O a lo largo del borde occidental del arco volcánico y una transpresión dextral de rumbo NNE en el antepaís. Los mecanismos focales de terremotos superficiales en el arco volcánico de Chile central, entre los $34^{\circ}$ y $35^{\circ} 30^{\prime} \mathrm{S}$, documentan desplazamientos de rumbo dextral a lo largo de estructuras de rumbo NNE, implicando un movimiento hacia el norte del bloque de antearco (Farías et al., 2006). Sin embargo, en el extremo norte de este tramo, a la latitud del volcán Maipo, se registró un sismo compresivo, con su eje de acortamiento NE, interpretado como resultante de un bloqueo de los movimientos transcurrentes dextrales, espacialmente asociados al oroclino del Maipo (Farías et al., 2006). Esta interpretación es consistente con el 'buttress' impuesto por la zona de subducción plana al norte de los $34^{\circ} \mathrm{S}$ (Lavenu y Cembrano, 1999b). Campos et al. (2002), en la zona de Concepción, $400 \mathrm{~km}$ más al sur, registraron sismos superficiales sobre fallas orientadas N20 a N30 ${ }^{\circ}$. Los mecanismos focales de estos casos caracterizan también un movimiento, hacia el norte, del bloque de la Cordillera de la Costa respecto de la Depresión Central, implicando un movimiento de rumbo dextral. La deformación cuaternaria descrita en este trabajo podría ser explicada por gradiente de velocidad N-S ('buttress'/bloqueo) del bloque rígido de antearco y partición de la deformación oblicuadextral (Lavenu y Cembrano, 1999b; Lavenu, 2006b; Cembrano et al., 2007) (Fig. 12).

Datos actuales de GPS que muestran acortamiento intersísmico paralelo al vector de convergencia y una extensión cosísmica, son solamente, en parte, compatibles con estructuras actuales observadas en terreno. No obstante, Allmendinger et al. (2006), a partir de los gradientes de velocidad GPS, obtienen que la dirección principal de acortamiento instantáneo ocurre en todas las direcciones del espacio a lo ancho de una amplia zona de orientación E-O, a la latitud $34^{\circ} \mathrm{S}$. Sólo el antearco externo presenta evidencias de extensión cortical cosísmica; el antearco interno no registra deformación significativa debida a un acortamiento E-O intersísmico. La compresión $\mathrm{N}-\mathrm{S}$, documentada en el antearco interno de Chile central (y sur) puede ser atribuida a una partición de la deformación cosísmica o intersísmica de la convergencia oblicua (Lavenu y Cembrano, 1999b; Lavenu, 2006b; Cembrano et al., 2007) contemporánea con un desplazamiento lateral hacia el norte del bloque de antearco, dentro del cual se produciría un gradiente de velocidad de sur a norte debido a un 'buttress' o un 'estribo' transversal representado por la heterogeneidad de la placa subductante de Nazca, a los $33^{\circ} \mathrm{S}$. Al norte de $34^{\circ} \mathrm{S}$ no hay mecanismos focales de rumbo en la Cordillera principal, pero sí los hay hacia el sur, implicando un cambio sustancial en la velocidad de transporte del antearco hacia el norte de esa latitud. 


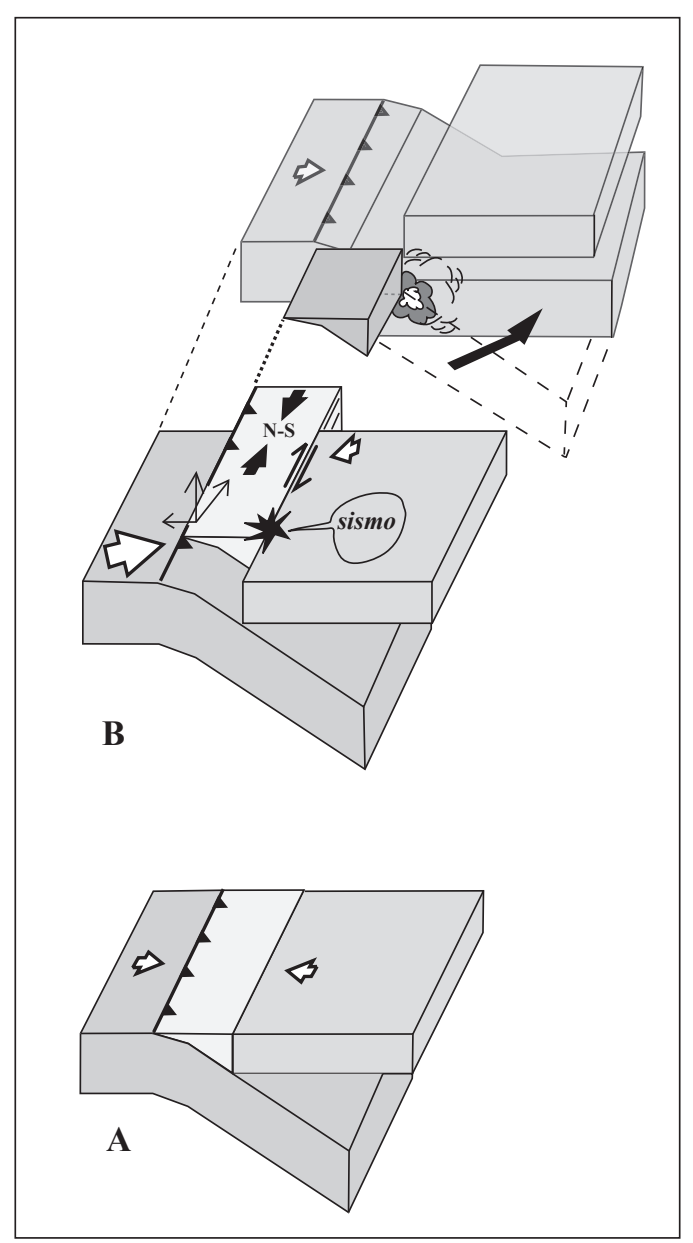

FIG. 12. Ilustración del estado de la deformación del margen activo (modificado de Cembrano et al., 2007). A. Situación del margen activo durante el estadio intersísmico; B. Estadio compresivo del antearco durante el estadio sísmico con desplazamiento relativo hacia el norte del bloque del antearco; bloqueo del movimiento hacia el norte debido al 'buttress' ejercido por la zona de 'flat slab'.

\subsection{Compatibilidad cinemática con sistemas de fallas regionales de Chile central}

Rauld (2002) describe la Falla San Ramón (FSR) (Figs. 3 y 5) como un sistema de rumbo $\mathrm{NO}$ a N-S, que ocurre en el borde occidental de la Precordillera al este de Santiago, y que corta depósitos de conglomerado de posible edad cuaternaria. Sobre la traza de la Falla San Ramón (Gana et al., 1999), en el flanco norte del Cerro Apoquindo, ocurren fallas inversas de rumbo $\sim \mathrm{E}-\mathrm{O}$ a NO-SE con cantos estriados que cortan y desplazan conglomerados recientes. Según Rauld (2002), la FSR sería una falla inversa con actividad cuaternaria bajo un esfuerzo predominante E-O. Una posibilidad es que la falla San Ramón, además de una componente inversa, tenga también una componente de rumbo dextral, lo que explicaría la compresión local $\mathrm{NE}$ en un 'restraining bend' de rumbo NO, tal como se observa en las fallas del Cerro Apoquindo (ver figura $1 \mathrm{de}$ Rauld et al., 2006).

En contraste, los datos presentados en este trabajo y en otros trabajos ya publicados (Lavenu y Cembrano, 1999b; McKinnon y Garrido, 2003; Allmendinger et al., 2005) indican un acortamiento discreto, aproximadamente N-S, para gran parte del antearco de los Andes chilenos durante el Cuaternario. Esta aparente contradicción podría explicarse mediante dos hipótesis alternativas: 1. la edad de la deformación por acortamiento E-O en la FSR sería precuaternaria, posiblemente pliocena; 2. habría una partición total de la deformación resultante de convergencia oblicua en una componente ortogonal acomodada en el borde occidental de la Cordillera Principal y otra, paralela a ésta, la cual sería acomodada al interior de la cordillera (cf. Zoback et al., 1987; Oldow et al., 1990; Rice, 1992; Zoback y Healy, 1992; Molnar, 1992; Tikoff y Tessier, 1994). La primera hipótesis parece ajustarse mejor a los datos, pues el episodio de acortamiento E-O que condujo al plegamiento de las unidades mesocenozoicas y al levantamiento de la parte occidental de la Cordillera Principal de Chile central puede remontarse al Mioceno (edad mínima de la Formación Abanico), consistente con las edades de trazas de fisión mio-pliocenas en el eje de la Cordillera Principal (e.g., Cembrano et al., 2003; Maksaev et al., 2004). En otras partes de la Cordillera de los Andes, se observa que durante este episodio de compresión E-O (de edad miocena y/o pliocena), la deformación de las rocas opera desde la Costa hacia la Cordillera Principal sin que haya partición de la deformación. Durante el episodio cuaternario de compresión N-S, se observa una partición siempre con dirección N-S a NNE-SSO en el antearco y NE-SO en el arco volcánico, pero nunca en dirección E-O. 


\section{Conclusiones}

Conglomerados pertenecientes a una antigua terraza fluvial cuaternaria (t5) del curso medio del río Maipo, están cortados por fallas inversas de rechazo centimétrico a métrico, las cuales documentan un acortamiento cuaternario principal, aproximadamente, N-S, dentro del dominio de la Cordillera Principal.

El análisis cinemático local de los planos de fallas en superficie no indica necesariamente el estado de esfuerzo global de la cordillera, la cual se ha encontrado sometida a un régimen de convergencia relativamente constante durante los últimos 10 millones de años, en magnitud y dirección.

El acortamiento N-S, sin embargo, ha dominado una porción significativa del antearco chileno entre la costa y la Cordillera Principal, inmediatamente al oeste del arco volcánico. Esta deformación, discreta en magnitud pero ampliamente distribuida, no puede resultar de un acortamiento E-O necesario para explicar todo el levantamiento de la cordillera mediante una falla inversa cuaternaria en el frente de montaña, a menos que dicha falla no aflore en superficie a los niveles actuales de erosión.

La sismicidad cortical superficial en la parte interna del antearco (Cordillera Principal) es -al menos en parte- compatible con la dirección de compresión obtenida a partir del análisis cinemático de las fallas mesoscópicas cuaternarias.

\section{Agradecimientos}

Este trabajo fue realizado en el marco de una investigación llevada a cabo gracias a la colaboración entre IRD (Francia), Universidad de Chile y CODELCO [Convenio IRD-Universidad de Chile, Convenio CODELCO-Universidad de Chile, Proyecto Geodinámico Mina El Teniente]. Especiales agradecimientos a los geólogos de la Mina El Teniente, I. Garrido, A. Siña, D. Espiñera por su asistencia. Los autores agradecen los valiosos comentarios y sugerencias realizados por R. Charrier, J. Skarmeta y G. Yáñez, quienes ayudaron a mejorar la versión original del manuscrito.

\section{Referencias}

Allmendinger, R.; González, G.; Yu, J.; Hoke, G.; Isacks, B. 2005. Trench-parallel shortening in the Northern Chilean Forearc: Tectonic and climatic implications. Geological Society of America Bulletin 117 (1-2): 89-104, doi: 10.1130/B25505.1.
Allmendinger, R.; Yáñez, G.; Cembrano, J. 2006. Instantaneous deformation associated with flat subduction: insights from GPS strain rates and numerical mode1ling. In Congreso Geológico Chileno, No. 11, Actas 1: 367-370. Antofagasta.

Araneda, M.; Avendaño, M.; Merlo, C. 2000. Modelo gravimétrico de la Cuenca de Santiago, etapa III final. In Congreso Geológico Chileno, No. 9, Actas 2: 404408. Puerto Varas.

Aubouin, J.; Audebaud, E.; Debelmas, J.; Dollfus, O.; Dresh, J.; Faucher, B.; Mattauer, M.; Mégard, F.; Paredes, J.; Savoyat, E.; Thiele, R.; Vicente, J.C. 1973. De quelques problèmes géologiques et géomorphologiques de la Cordillère des Andes. Revue de Géographie physique et de Géologie dynamique 15 (1-2): 207-216.

Barrientos, S.; Eisenberg, A. 1988. Secuencia sísmica en la zona cordillerana al interior de Rancagua. In Congreso Geológico Chileno, No. 5, Actas 2: F121F132. Santiago.

Barrientos, S.; Vera, E.; Alvarado, P.; Monfret, T. 2004. Crustal seismicity in central Chile. Journal of South American Earth Sciences 16: 759-768.

Campos, J.; Hatzfeld, D.; Madariaga, R.; López, G.; Kausel, E.; Zollo, A.; Innacone, G.; Fromm, R.; Barrientos, S.; Lyon-Caen, H. 2002. A seismological study of the 1835 seismic gap in the South Central Chile. Physical Earth Planetary Interior 132: 177-195.

Carey, E.; Mercier, J.L. 1989. Software E.C.G.-GEOLDYNSOFT-5.0.

Carter, W.; Aguirre, L. 1965. Structural geology of Aconcagua province and its relationship to the central valley graben, Chile. Geological Society of America Bulletin 76: 651-664.

Cembrano, J.;Zentilli, M.; Yáñez, G. 2003. Nuevas edades de trazas de fisión para Chile Central (30-34 $\mathrm{S})$ : Implicancias en la exhumación y alzamiento de los Andes desde el Cretácico. In Congreso Geológico Chileno, No. 10, Actas, CD-ROM. Concepción.

Cembrano, J.; Lavenu,A.; Yáñez, G.; Riquelme, R.; García, M.; González, G.; Hérail, G. 2007. Neotectonics. In The geology of Chile (Moreno, T.; Gibbons, W.; editors). The Geological Society, London: 231-261.

Charrier, R.; Baeza, O.; Elgueta, S.; Flynn, J.J.; Gans, P.; Kay, S.; Muñoz, N.; Wyss, A.R.; Zurita, E. 2002. Evidence for Cenozoic extensional basin development and tectonic inversion south of the flat-slab segment,

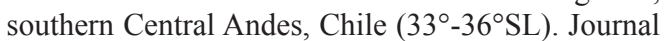
of South American Earth Sciences 15: 117-139.

Charrier, R.; Wyss, A.R.; Flynn, J.J.; Swisher, C.C.; Norell, M.A.; Zapatta, F.; McKenna, M.C.; Novacek, M.J. 1996. New evidence for Late Mesozoic-Early Cenozoic evolution of the Chilean Andes in the Upper Tinguiririca Valley $\left(35^{\circ} \mathrm{S}\right)$, Central Chile. Journal of South American Earth Sciences 9: 393-422.

Cornejo, P. 1991. Geology, mineral compositions and magmatic gradients of a zoned pluton: La Gloria pluton, Central Chilean Andes. Msc. Thesis (Unpublished), 
Stanford University: $160 \mathrm{p}$.

Costa, C.; Audemard, F.; Bezerra, H.; Lavenu, A.; Machette, M.; Paris, G. 2006. An overview of the main Quaternary deformation of South America. Revista de la Asociación Geológica Argentina 61 (4): 461-479.

Doblas, M. 1998. Slickenside kinematic indicators. Tectonophysics 295: 187-197.

Doblas, M.; Mahecha, V.; Hoyos, M.; López-Ruiz, J. 1997. Slickenside and fault surface kinematic indicators on active normal faults of the Alpine Betic cordilleras, Granada, southern Spain. Journal of Structural Geology 19 (2): 159-170.

Eidelman, A.; Reches, Z. 1992. Fractured pebbles-A new stress indicator. Geology 20: 307-310.

Elgueta, S.; Baeza, O.; Aguirre, R.; Charrier, R.; Muñoz, N.; Gans, P. 2000. Mecanismos de la depositación volcanoclástica Oligo-Miocena del Cajón del Maipo, Chile Central. In Congreso Geológico Chileno, No. 9, Actas 2: 21-25. Puerto Varas.

Farías, M.; Charrier, R.; Fock, A.; Campbell, D.; Martinod, J.; Comte, D. 2005. Rapid Late Cenozoic surface uplift of the central Chile Andes $\left(33^{\circ}-35^{\circ} \mathrm{S}\right)$. In International Symposium on Andean Geodynamics (ISAG), No. 6: 261-265. Barcelona.

Farías, M.; Comte, D.; Charrier, R. 2006. Sismicidad superficial en Chile central: implicancias para el estado cortical y crecimiento de los Andes centrales australes. In Congreso Geológico Chileno, No. 11, Actas 2: 403-406. Antofagasta.

Flynn, J.J.; Wyss, A.R.; Croft, D.A.; Charrier, R. 2003. The Tinguiririca Fauna, Chile: biochronology, paleoecology, biogeography, and a new earliest Oligocene South American Land Mammal 'Age'. Palaeogeography, Palaeoclimatology, Palaeoecology, 195 (3-4): 229-259.

Fock, A.; Charrier, R.; Farías, M.; Muñoz, M. 2006. Fallas de vergencia oeste en la Cordillera Principal de Chile Central: inversion de la cuenca de Abanico $\left(33^{\circ}-34^{\circ} \mathrm{S}\right)$. Asociación Geológica Argentina, Serie: Publicación especial 6: 48-55.

Fuentes, F. 2004. Petrología y metamorfismo de muy bajo grado de unidades volcánicas oligoceno-miocenas en la ladera occidental de los Andes de Chile central $\left(33^{\circ} \mathrm{S}\right)$. Tesis de doctorado (Inédita), Universidad de Chile, Departamento de Geología: 398 p.

Gana, P.; Sellés, D.; Wall, R. 1999. Area Tiltil-Santiago, Región Metropolitana. Servicio Nacional de Geología y Minería, Mapas Geológicos No. 11, escala 1:100.000. Santiago.

Gana, P.; Wall, R. 1997. Evidencias geocronológicas ${ }^{40} \mathrm{Ar} /{ }^{39} \mathrm{Ary} \mathrm{K}-\mathrm{Ar}$ de un hiatus Cretácico Superior-Eoceno en Chile central (33-3330'S). Revista Geológica de Chile 24 (2): 145-163.

Hippolyte, J.C. 2001. Paleostress and neotectonic analysis of sheared conglomerates: southwest Alps and southern Apennines. Journal of Structural Geology 23: 421-429.
Howard, A.D. 1967. Drainage analysis in geologic interpretation: a summary. American Association of Petroleum Geologists, Bulletin 51: 2246-2259.

Kay, S.; Mpodozis, C. 2002. Magmatism as a probe to the Neogene shallowing of the Nazca plate beneath the modern Chilean flat-slab. Journal of South American Earth Sciences 15: 39-57.

Lavenu, A. 2006a. Neotectónica de los Andes entre $1^{\circ} \mathrm{N}$ y $47^{\circ} \mathrm{S}$ (Ecuador, Bolivia y Chile): una revisión. Revista de la Asociación Geológica Argentina 61 (4): 504-524.

Lavenu, A. 2006b. Fallas cuaternarias en Chile. Servicio Nacional de Geología y Minería, Boletín 62: 71 p.

Lavenu, A.; Cembrano, J. 1999a. Estados de esfuerzo compresivo plioceno y compresivo-transpresivo pleistoceno, Andes del sur, Chile (38-42 $\left.{ }^{\circ} 30^{\prime} \mathrm{S}\right)$. Revista Geológica de Chile 26 (1): 67-87.

Lavenu, A.; Cembrano, J. 1999b. Compressional- and transpressional-stress pattern for Pliocene and Quaternary brittle deformation in fore arc and intra-arc zones (Andes of Central and southern Chile). Journal of Structural Geology 21 (12): 1669-1691.

Lavenu, A.; Thiele, R.; Cembrano, J. 1994. Neotectónica compresiva plio-cuaternaria en la Depresión central de Chile. In Congreso Geológico Chileno, No. 7, Actas 1: 324-328. Concepción.

Lavenu, A.; Thiele, R.; Machette, M.; Dart, R.; Bradley, L-A.; Haller, K. 2000. Maps and Database of Quaternary Faults in Bolivia and Chile. United States of Geological Survey, Open-File Report 00-283: 50 p.

Le Roux, J.P.; Gómez, C.; Venegas, C.; Fenner, J.; Middleton, H.; Marchant, M.; Buchbinder, B.; Frassinetti, D.; Marquardt, C.; Buchbinder, B.; Gregory-Wodzicki, K.M.; Lavenu, A. 2005. Neogene-Quaternary coastal and offshore sedimentation in north-central Chile: Record of sea level changes and implications for Andean tectonism. Journal of South American Earth Sciences 19: 83-98.

Lomnitz, C. 1961. Los terremotos del 4 de Septiembre de 1958 en el Cajón del Maipo. Anales de la Facultad de Ciencias Físicas y Matémáticas 18: 279-306.

Machette, M. 2000. Active, capable and potencially Active Faults-A paleoseismic perspective. Journal of Geodynamics 29: 387-392.

Mackin, J.H. 1948. Concept of the graded river. Geological Society of America Bulletin 5: 463-511.

Maksaev, V.; Munizaga, F.; McWilliams, M.; Fanning, M.; Mathur, R.; Ruiz, J.; Zentilli, M. 2004. New Chronology for El Teniente, Chilean Andes, from U-Pb, ${ }^{40} \mathrm{Ar} /{ }^{39} \mathrm{Ar}$, Re-Os, and Fission-Track Dating: Implications for the Evolution of a Supergiant Porphyry Cu-Mo Deposit. In Andean Metallogeny: New Discoveries, Concepts and Updates (Sillitoe, R.H.; Perelló, J.; Vidal, C.E.; editors). Society of Economic Geologists, Special Publication 11: 15-54. Boulder.

Marrett, R.; Allmendinger, R. 1990. Kinematic analysis of fault-slip data. Journal of Structural Geology 12 (8): 973-986. 
McEwen, T.J. 1981. Brittle deformation in pitted pebble conglomerates. Journal of Structural Geology 3: 25-37.

McKinnon, S; Garrido, I. 2003. Stress field analysis at the El Teniente Mine: evidence for N-S compression in the modern Andes. Journal of Structural Geology 25: 2125-2139.

Molnar, P. 1992. Brace-Goetze strenght-profiles, the partitioning of strike-slip and thrust faulting at zones of oblique convergence, and the stress-heat flow paradox of the San Andreas fault. In Fault mechanics and transport properties of rocks (Evans, B.; Wong, T.F.; editors). Academic Press: 435-459. New York.

Nyström, J.O.; Vergara, M.; Morata, D.; Levi, B. 2003. Tertiary volcanism during extension in the Andean foothills of central Chile ( $\left.33^{\circ} 15^{\prime}-33^{\circ} 45^{\prime} \mathrm{S}\right)$. Geological Society of America Bulletin 115 (12): 1523-1537.

Oldow, J.S.; Bally, A.W.; Avé Lallement, H.G. 1990. Transpression, orogenic float, and lithospheric balance. Geology 18: 991-994.

Ormeño, A. 2007. Geomorfología dinámica del Río Maipo en la zona cordillerana de Chile central e implicancias geotectónicas. Memoria de Título (Inédito), Universidad de Chile, Departamento de Geología: 147 p.

Pardo, M.; Monfret, T.; Vera, E.; Eisenberg, A.; Yáñez, G. 2004. Crustal seismicity in the central Chile-western Argentina Andes cordillera. In Geophysical Research Abstracts 6, EGU 04-A-04452.

Pardo, M.; Vera, E.; Monfret, T.; Yáñez, G.; Eisenberg, A. 2006. Sismicidad cortical superficial bajo Santiago: implicaciones en la tectónica andina y evaluación del peligro sísmico. In Congreso Geológico Chileno, No. 11, Actas 2: 443-446. Antofagasta.

Petit, J.P. 1987. Criteria for the sense of movement on fault surfaces in brittle rocks. Journal of Structural Geology 9 (5-6): 597-608.

Petit, J.P.; Reynaud, S.; Cautru, J.P. 1985. Microtectonique cassante lors du plissement d'un conglomérat (MioPliocène du Haut Atlas-Maroc). Bulletin de la Société géologique de France, Serie 8, 1 (3): 415-421.

Rauld, R. 2002. Análisis morfoestructural del frente cordillerano de Santiago oriente, entre el Río Mapocho y la Quebrada de Macul. Memoria de Título (Inédito), Universidad de Chile, Departamento de Geología: 57 p.

Rauld, R.; Vargas, G.; Armijo, R.; Ormeño, A.; Valderas, C.; Campos, J. 2006. Cuantificación de escarpes de falla y deformación reciente en el frente cordillerano de Santiago. In Congreso Geológico Chileno, No. 11, Actas 2: 447-450. Antofagasta.

Rice, J.R. 1992. Fault stress states, pore pressure distributions, and the weakness of the San Andreas fault.
In Fault mechanics and transport properties of rocks (Evans, B.; Wong, T.F.; editors). Academic Press: 475-503. New York.

Riquelme, R.; Hérail, G.; Martinod, J.; Charrier, R.; Darrozes, J. 2007. Late Cenozoic geomorphologic signal of Andean forearc deformation and tilting associated with the uplift and climate changes of the Southern Atacama Desert $\left(26^{\circ} \mathrm{S}-28^{\circ} \mathrm{S}\right)$. Geomorphology 86 (3-4): 283-306.

Riquelme, R.; Martinod, J.; Hérail, G.; Darrozes, J.; Charrier, R. 2003. A geomorphological approach to determining the Neogene to Recent tectonic deformation in the Coastal Cordillera of northern Chile (Atacama). Tectonophysics 361 (3-4): 255-275.

Ruano, P.; Galindo-Zaldívar, J. 2004. Striated and pitted pebbles as paleostress markers: an example from the central transect of the Betic Cordillera (SE Spain). Tectonophysics 379: 183-198.

Salazar, P. 2005. Análisis del campo de esfuerzo en la zona de subducción bajo Chile central $\left(30^{\circ}-34^{\circ} \mathrm{S}\right)$. Memoria de Título (Inédito), Universidad de Chile, Departamento de Geofísica: 183 p.

Schumm, S.; Dumont, J.F.; Holbrook, J. 2000. Active tectonics and alluvial rivers. University Press, Cambridge: $276 \mathrm{p}$.

Stern, C.; Amini, H.; Charrier, R.; Godoy, E.; Hervé, F.; Varela, J. 1984. Petrochemistry and age of rhyolitic flows which occur along the drainage valleys of the río Maipo and río Cachapoal (Chile) and the río Yaucha and río Papagayos (Argentina). Revista Geológica de Chile 23: 39-52.

Thiele, R. 1980. Hoja Santiago, Región Metropolitana: Santiago. Instituto de Investigaciones Geológicas, Carta Geológica de Chile 39: 51 p.

Tikoff, B.; Tessier, C. 1994. Strain modeling of displacement-field partitioning in transpressional orogens. Journal of Structural Geology 16: 1575-1588.

Wall, R.M.; Lara, L.E.; Pérez de Arce, C. 2001. Upper Pliocene-Lower Pleistocene ${ }^{40} \mathrm{Ar} /{ }^{39} \mathrm{Ar}$ ages of Pudahuel ignimbrite (Diamante-Maipo volcanic complex), Central Chile $\left(33.5^{\circ} \mathrm{S}\right)$. In Simposio Sudamericano de Geología Isotópica, No. 2, Actas, CD-ROM. Pucón.

Zoback, M.D.; Healy, J.H. 1992. In situ stress measurements to $3.5 \mathrm{~km}$ depth in the Cajon Pass scientific research borehole: implications for the mechanics of crustal faulting. Journal of Geophysical Research 97: 5039-5057.

Zoback, M.D.; Zoback, M.L.; Mount, V.S.; Suppe, J.; Eaton, J.P.; Healy, J.H.; Oppenheimer, D.; Reasenberg, P.; Jones, L.; Raleigh, C.B.; Wong, I.G.; Scott, O.; Wentworth, C. 1987. New evidence on the state of stress of San Andreas fault system. Science 238: 1105-1111.

Manuscrito recibido: mayo 10, 2007; aceptado: marzo 26, 2008. 